\title{
ON A COLLECTION OF CHILEAN LANDPLANARIANS
}

\author{
Eudoxia Maria Froehlich
}

\begin{abstract}
Nine species are added to the inventory of Chilean species of Tricladida Terricola, seven are presented here and two will be presented in a future paper; two species, also worked here, were already known, Geoplana chilensis and Geoplana cruciata, the latter removed to a new genus; Microplana ruca Marucs, really a Geoplana is redescribed.

Three new genera are erected: Gusana, Timyma and Liana. From them, the second onde, coming from an isolated wood with relict plant species, shows some primitive characters untill now exclusive of the Oriental and Notogeic Geoplanids.

The worms come from several localities, from the arid "Norte Chico", till Nahuelbuta in the forest zone.
\end{abstract}

\section{INTRODUCTION}

The material studied here is the major part of a collection, kindly sent from Chile by Prof. Dr. F. DiCastri, to whom I am very grateful. The 58 specimens of the collection were acompanied by informations about their respective habitats, which ranged from the arid "Norte Chico" to Nahuelbuta in the forest zone.

The worms belong to 12 species of Geoplanidae: two are new findings, one is restudied and renamed; 9 are new. Five species, among which one of those already known, constitute 4 new genera.

Of the 12 species 10 are studied here. The remaining two, belonging to one of the new genera, will be described in a future paper. All this material was included by C.G. Froehlich in his study of the zoogeography of the neotropical land planarians and the great interest of some of them was emphasized (C.G. Froehlich, 1957). Based on characteristics of the copulatory apparatus the same author indicated the necessity of creating a new genus to accommodate four of the above species. This genus parallels the Notogeic genus Artioposthia in possessing muscular gland organs in the copulatory 
apparatus. One of the four species, $G$. ercilla sp. nov. being more accurately studied here, showed a closer relationship to a peruvian species of Geoplana. The three remai-. ning species are really only two and form the new genus yet to be described. Finally, C.G. Froehlich indicated that a fifth species, whose zoogeographical importance he stressed should constitute another new genus. This is described here.

Eighteen species of Geoplanidae were already known from Chile. One species belongs to the monotypic genus Polycladus. The remaining 17 species belong to the genus Geoplana, all of them, two excepted, being known only through their external morphology. The exceptions are G. ruca Marcus, placed originally among the Rhynchodemidae and $G$. pulla Graff. This latterspecies is known from heterogeneous ma. terial and the locality of the sectioned worm was not indicated.

Thus the Terricola from Chile sum 27 species, including those here presented and the two left for a next paper, all belonging to the family Geoplanidae.

\section{MATERIAL AND METHODS}

For all the worms studied serial sagittal sections of the compulatory apparatus and of the pharynx, $12 \mu \mathrm{m}$ thick, were made.

The study of musculature, nervous system, sensory and glandular border and of the topography of the male and female ducts was based on serial transversal sections 5 to $8 \mu \mathrm{m}$ thick. Hematoxylin and eosin were used for staining.

All measurements and the distance of the mouth and of the gonopore from the anterior tip are given in millimeters. The $\mathrm{mc}: \mathrm{h}$ index is the relation, expressed in percentual, between the sum of the heights of the ventral and dorsal cutaneous musculature and the height of the worm, anterior to the pharynx.

The whole material examined, including the types of the new species, and the drawings of their respective colour patterns are deposited in the Departamento de Zoologia do Instituto de Biociências da Universidade de São Paulo.

The drawings of the copulatory apparatus result from a combination of drawings from several sections made with the aid of a camera lucida. The pharynx and the details from the sections were also drawn with the aid of the camera lucida. Other drawings are free-hand.

Gusana gen. nov.

\section{DIAGNOSIS}

Geoplanidae with broad, foliaceous body, tapering very abruptly to the anterior end. Anterior end triangular. Creeping sole broad, with more than half the body width. Subepidermal musculature weak; longitudinal layer partly sunk into the parenchyma, internal to the cutaneous nerve net, both ventrally and dorsally. Sensory border forming a thick turned edge around anterior tip. Sensory pits of normal shape or obliquely 
elongated and internally branched. Testes dorsal. Without adhesive musculo-glandular organs and sensory papillae. Copulatory apparatus without adenodactyls.

Type species:

Gusana cruciata (Graff), 1899.

\section{DISCUSSION:}

The sensory border of Gusana differs in its width and structure from the sensory border of Geoplana. In addition none of the other genera of Geoplanidade, more distantly related to Gusana in other aspects have a similar sensory border. Up to eight sensory pits on the same side of a transverse section may occur in Gusana. In general, broader species of Geoplana have a greater number of sensory pits than the narrow species. In the broader species the pits are not arranged in regular logitudinal lines, but gather on both sides along the sensory border. However the sensory border differs externally from the remaining body surface only by the lack of pigment, appearing generally as a white line between dorsal and ventral surfaces. In the broader species the maximum of 3 or 4 pits occur on the same side of a transverse section. In $G$. divae Marcus, e.g., a species up to $160 \mathrm{~mm}$ long by $15 \mathrm{~mm}$ broad, there was, in a transverse section $4,2 \mathrm{~mm}$ broad, through the anterior tip, the maximum number of 3 pits on one side and 2 on the other in a sensory border $130 \mu \mathrm{m}$ broad, from the most external pit to the most internal one. However, these pits are never obliquely elongated, or branched.

Describing the sensory border of several Australian species, Dendy (1899) says that in some species, notably $G$. spenceri, the light line tends to become grooved or furrowed transversely, with the sensory pits lying in the transverse grooves as figured by Moseley for Bipalium. He figures the anterior end of $G$. spenceri (1.c., Plate 5, fig. 8) showing transverse grooves connected by a longitudinal furrow and remarks that "such furrows might easily be mistaken for artificial wrinkling due to the action of spirit"

I' could observe the same wrinkling in a specimen of $G$. spenceri presented to me by Dr. L. Winsor, to whom I am very indebted. Transverse sections through its anterior end confirmed the artificial nature of the furrows. The tissues of sensory border (epidermis and parenchyma) are greatly vacuolated with many of the lacunae full of strong erythrophilous secretion. This structure is perhaps accountable for the tendency of wrinkling displayed by the sensory border of this species. The sensory pits proper are canals, a little longer (up to $55 \mu \mathrm{m}$ ) than the usual, receiving into their dilated intraparenchymal portion many glandular ducts with a coarse cyanophilous secretion. I have never seen, up to now, any glands opening into the sensory pits of landplanarians. Neither did Graff (1899 and 1914) mention any glands associated with "Sinnes grubchen" although drawing something like them in G. munda (Plate 24, fig. 2). 
Artioposthia grubei Graff is also described by Graff $(1899$, pg. 132) as having a more complex sensory border with sensory pits in the middle of thin transverse furrows, resembling that of Bipalium kewense. The description however is superficial, and Graff only reproduces Moseley's drawing of the external aspect of the sensory border of the latter species, which does not resemble that of Gusana.

Xerapoa by the structure of its sensory border also stands alone among all the Geoplanids. Here, however, the sensory pits, of normal shape, open separately at the tip of extensible papillae.

In correspondence with the greater width of the sensory border there is an ample extension of transversal connections between the ventral nerve plate and the subcutaneous nerve net, at both sides of the body. This may contribute to the greater thickness of the sensory border in relation to the remaining body surface.

Longitudinal cutaneous musculature partly inward the subcutaneous nerve system occurs also in Choeradoplana where it occurs only on the ventral side. Probably it serves as an antagonist of the dorsal bundles of the longitudinal cutaneous muscles, which contracting curls up the anterior part of the body. At this end, where glandular cushions are situated, there is a greater distance between the internal layer of longitudinal musculature and the body surface, so that it looks like an independent parenchymal layer and not derived of the cutaneous layer. In Gusana this internal layer has the same position relatively to the body surface all along the body. Besides this, Choeradoplana has contrary to Gusana a very strong normal logitudinal layer, especially at the dorsal side.

The very short and abruptly narrowed anterior tip could be accentuated by the great contraction of the musculature of worms killed with cold fixative but it is constant in my three specimens as well as in Graff's specimen.

The incompletely mature worms in inadequate histological conditions did not allow a more detailed study. In consequence only the gross aspects of glands, of structure of the epithelium of the sensory border and of the epithelium of the creeping sole could be ascertained. The rhabdoids are mostly of the chondrocyst type excepting those of the creeping sole which are small rhabdites.

Cyanophilous glands are rare dorsaly but abundant in the sole. The epithelium of the sensory border is of the insunk type and devoid of cilia. Glands associated with it could not be discerned.

I suspect that Geoplana platei which approaches Gusana cruciata by the shape and locality, and that was described by Graff as possessing a sensory border clearly visible, is another species to be assigned to Gusana.

Gusana cruciata (Graff, 1899)

(Figs. 1-9, 18 and 68-71)

Geoplana cruciata, 1899 , pg. 316

Geoplana cruciata C.G. Froehlich, 1967, pg. 160.

Type material

Localization unknown. 


\section{MATERIAL EXAMINED}

Ten slides with sets of longitudinal sections of the rear portion passing through the pharynx and copulatory apparatus of speciman $a$; remainder portion in alcohol. Sets of longitudinal sections through the pharynx on nine slides; six slides with sets of frontal sections of the anterior portion, from the tip up to the pharynx of specimen $b$; rest of worm in alcohol. One juvenile worm in alcohol.

\section{DISTRIBUTION}

Nahuelbuta, Provincia Malleco, 16 December 1961, 1 incompletely mature specimen (a). Isla Mancera, Province of Valdivia, 2 October 1964, 1 imature specimen (b). Lago Calafquen, Province of Valdivia, 2 October 1964, 1 imature specimen (c). The three localities are situated in the hygrophilous temperate forest zone where several species of Notophagous are the dominant tree species. Nahuelbuta also has, as a dominant species, Araucaria araucana.

Original locality - Tumbes, peninsula to the North of Concepcion.

\section{DESCRIPTION}

Small worms, with a rather high body of uncommon shape. Anterior point somewhat triangular, very short and abruptely narrowed in comparison with the major body width, situated, in three specimens, in the anterior half. Specimen $b$, of which the index $\mathrm{mc}: \mathrm{h}=2,8 \%$, is strongly contracted; specimen $c$ is strongly contracted and fragmented.

\section{MESUREMENTS}

$\begin{array}{crcccc}\text { Specimen } & \text { Length } & \text { Width } & \text { Height } & \text { Mouth } & \text { Gonopore } \\ \text { a } & 12,5 & 4,9 & 1,4 & 7,6 & 9,9 \\ \text { b } & 9,1 & 4 & 1,2 & 5,4 & - \\ \text { c } & 7,2 & 3 & - & - & -\end{array}$

Dorsal side brownish black, darker in specimens $b$ and $c$. Along the median line there is a light stripe and, a little behind the anterior end, there is a collar that forms with the first the cross from which the species get its name (Fig. 1). The transverse and the posterior arms of the cross are ferruginous, the anterior arm greyish. Specimen $c$ has not the posterior arm. At the ventral side there are four black mottled lon- 
gitudinal bands over a white ground, and an anterior ferruginous collar continuous with the dorsal one (Fig. 2).

In specimen $b$ the dark pigment is less concentrated at the sides of the body and the marginal eyes could be seen in the cleared worm along a single file from the anterior tip up to the posterior one (Figs. 3-4). They have 30 to $45 \mu \mathrm{m}$ in diameter. In specimen $a$ they were seen only around the anterior tip up to the collar, in the middle of white halos.

At the anterior extremity the margins of the body form a relatively thick turned edge devoid of pigment, that narrows progressively towards its posterior end, and situated $1,3 \mu \mathrm{m}$ behind the tip in specimen $b$. Under the stereomicroscope, with strong light, the sensory pits could be seen on the edge along a single irregular file. The anterior tip of specimen $c$ and of specimen $b$ is strongly contracted with transverse wrinkles (Fig. 5). The pits are nearly circular around the tip (Fig. 68). On the wrinkled portion they are obliquely elongated and the wrinkles start from each one of them.

The dorsal epithelium is abundantly provided with rhabdoids of the chondrocyst type, besides the more common types, which are mostly rhammites. Ventral epithelium with few, small rhabdites.

The subepidermal musculature forms a thin layer, ca. $16 ; \mathrm{m}$ high, outer to the cutaneous nervous system. However, muscle fibres of longitudinal layer can be seen crossing the cutaneous nerve net to form a parenchymal longitudinal layer. At the ventral side, this parenchymal layer extends to the ventral nerve plate (Fig. 9). Laterally it almost reaches the margins of the body, except on the anterior tip where it ends at the sensory border. From side to side it has the same extension as the creeping sole. In a transverse section, ca $1 \mathrm{~mm}$ in front of the pharynx, the width of the worm was 3,8 and that of the creeping sole $3 \mathrm{~mm}$. In the subcutaneous portion the logitudinal muscle fibres do not form the typical parallel bundles. Instead they are arranged there as small irregular bundles at most with 6 fibres. In the parenchymal portion the fibres alsoform irregularly arranged bundles with 3 to 12 fibres. Dorsally there is a more clear division between the two layers of longitudinal muscles, and the fibres passing from the external layer to the internal one are more rarely observed. Here the parenchymal layer consists of isolated fibres and of small bundles of 2 to 3 fibres, both scattered through the whole parenchyma between the cutaneous nerve net and the intestine. They form, plus the transversal, the diagonal and the dorsoventral parenchymal muscles fibres e a dense network.

The true parenchymal muscles are fibres running obliquely in the transverse plane, specially numerous on the sides of the body; fibres running obliquely in the sagittal plane and dorsoventral fibres running between the intestinal diverticles.

The obliquely elongated sensory pits appear in several successive transversal sections. Begining anteriorly, on the lateral margins of a section, they proceed posteriorly and medially in subsequent sections at the same time that other begin on the margins (Figs. 69-71). Along their path they may exhibit 1 to 3 diverticles, which arise from the botton or from the sides (Figs. 70-71). There are also pits of common type, that is, they have a narrow neck crossing the epidermis and an expanded round basal chamber in the parenchyma. Besides these, still smaller ones, have only the narrow neck crossing obliquely the epidermis, lacking the expanded chamber. In the transverse sections, 
$6 \mu \mathrm{m}$ thick, there may de 1 to 8 sections of pits on the same side (Fig. 6-7, Fig. 70). They are sections of pits that have begun anteriorly, of their respective diverticles, when they are branched, and of pits that are beginning. the most anterior pits, of the common type, are about $20 \mu \mathrm{m}$ wide at the expanded chamber, and 40 to $60 \mu \mathrm{m}$ deep, and they appear at most on 4 successive sections. One elongated pit, present in 7 successive sections was measured; it was $49 \mu \mathrm{m}$ long, $40 \mu \mathrm{m}$ deep and $15 \mu \mathrm{m}$ wide. It has 2 diverticles, one to the left and more anterior, present in 4 sections, another to the rigth, beginning posteriorly to the first, also present in 4 sections. Another elongated pit was $52 \mu \mathrm{m}$ deep at the begining on the margin of the section. In a transverse section, $1 \mathrm{~mm}$ behind the anterior tip, and $2,7 \mathrm{~mm}$ wide, the sum of the width of the sensory borders of both sides was $1,6 \mathrm{~mm}$, that is, a little less than half the total width. There are plenty of connections between the ventral nerve plate and the cutaneous nerve net supplying the sensory border, and forming a dense nerve net on both sides of the worm.

Pharynx of the cylindrical type, occupying the whole pocket; mouth on the posterior end of the pocket (Fig. 18).

Dorsal testes extending up to the pharynx. They are ripe in specimen $a$, but in specimen $b$ they are still massive and begin about $2 \mathrm{~mm}$ behind the anterior tip and $1 \mathrm{~mm}$ behind the ovaries.

The efferent ducts dilate into tortuous spermiducal vesicles which extend beyond the anterior level of the prostatic vesicle, then recurve anteriorly and ascend obliquely (Fig. 8). Their entry into the vesicle could not be seen, they appear abruptly interrupted. However, as it was remarked before, the histological conditions are not good, and the ectal portions of efferent ducts, without spermatozoa, are presumably very thin.

Despite the spermiducal vesicles full of sperm the copulatory apparatus seems to be incomplete in its development and histological differentiation. The prostatic vesicle is internal to the common muscular coat and very close to the pharyngeal pocket. It is a tube with the ental portion straight, and wider than the ectal onde, sinuous, with half the diameter of the first. From the vesicle the ejaculatory ducts traverses the center of the little cylindrical penis papilla. The epithelium lining the vesicle as well as the duct has a variable height and is taller in the former. The intrinsic musculature is thin and there is an incompletely diferenciated tissue, apparently of glandular nature, running along the vesicle and the duct. Also glandular seems to be the tissue that fills a great portion of both the bulb and the penial papilla besides accompanying the major part of the adjacent wall of the male atrium. The small penial papilla, directed obliquely unpwards, occupies only the innermost enlarged portion of the male atrium. Following this portion the atrial cavity becomes narrower and lined by a tall epithelium. This portion leads to a common dilated atrium lined, anterior to the gonopore, by a low epithelium that becomes taller in the female portion. Dorsally at the botton of this latter, a little behind the gonopore, opens the vagina.

Posterior to the gonopore the oviducts turn medially. Along this, somewhat ascendent, transverse course they receive the shell glands. At the medial plane they unite forming the common glandular duct that travels dorsoanteriorly to meet the horizontal vagina. 


\section{DISCUSSION}

Graff's description of external aspects fits well to my specimens, although these have the pigment of the dorsal face homogeneously distributed and not forming longitudinal bands. As regards the eyes, Graff was also unable to see them behind the clear collar, as is the case of specimen $a$. The localities are little apart.

Another Chilean species, G. platei, from a little more distant locality, but similar biotope, could be conspecific with $G$. cruciata. Both the form of the body and the colour pattern are very similar.

Nevertheless, as its internal anatomy is not known it is better to keep it separeted from $G$. cruciata.

Timyma, gen. nov.

\section{DIAGNOSIS}

Geoplanidae with elongated body ending abruptly in a wide anterior extremity. Longitudinal cutaneous musculature weak and logintudinal parenchymal musculature absent. Sensory border circling the anterior end and restricted to it. Ventral testes opening directly into the efferent ducts which run over the central nerve plate. Without adhesive musculo-glandular organs or sensory papillae. Copulatory apparatus without adenodactyls.

Type species

Timyma juliae, sp.n.

\section{DISCUSSION}

The form of the anterior tip is such that the worms were registered, at first sight, as two posterior fragments. A similar anterior extremity occurs only among the Bipaliids, an essentially Oriental group, in which a cephalic plate is always distinct from the remaining body and the creeping sole is always narrow. Wide creeping sole combined with eyes all along the margins are external features diagnostic of the family Geoplanidae.

A sensory border, restricted to the ventral anterior margin of the body, consisting of short epidermic furrows oriented somewhat obliquely to the antero-posterior axis is a peculiar structure. Besides the sensory pits that open at the bottom of the most lateral furrows, up to four at each side, it presents between two consecutive furrows small epidermic papillae. In the most anterior transverse sections, these furrows and papillae form a continuous line from side to side (Figs. 73-75). The papillae seem to be similar to the ones described by Moseley and by Graff for the Bipaliidae. However 
in the Bipaliidae the sensory border is marginally placed, and the furrows and papillae are vertically oriented (Graff, 1899, pag. 132, fig. 12 and Plate XXXVI, fig. 6).

Both the form of the cephalic extremity and the structure of the sensory border are important as diagnostic features and at least the first is a derived condition.

On the other side, ventral testes directly connected with efferent ducts dorsal to the nervous system, all of them also important as diagnostic characters in Timyma, are considered primitive in the Terricola (C.G. Froehlich, 1967).

In the true Neotropical Geoplanids hereto known, except for G. guacensis Fuhrman, of doubtful systematic position and for $G$. mexicana Hyman also of doubtful both systematic position and origin, the testes are dorsal and the efferent system is allways completely dorsal to the ventral nerve plate.

So, ventral testes are shared by Timyma only with Oriental and Notogeic Geoplanids that have, however, at least the more ental part of the efferent system, below the ventral nerve plate, what is considered a derived condition.

Also considered a derived condition in the Terricola is the combination of weak cutaneous musculatures with absence of longitudinal muscles. This condition is another feature approaching Timyma to the Coenoplana like geoplanids, chiefly Australian C.G. Froehlich, 1955 and 1967 and Beauchamp 1961), as all other Neotropical genera generally combine absence of a true longitudinal parenchymal musculature with strong cutaneous muscles.

From what has been said and on account of its ocurrence in the old hygrophilous forest of Fray Jorge, isolated by arid surroundings, Timyma juliae could be thought as relict of one of the branchs, the less vigorous one, into which the Neotropical sister branch of Coenoplana-like geoplanids has split; and the more vigorous branch comprising Geoplana and the closely related genera Choeradoplana, Xerapoa and Issoca. The Neotropical geoplanids as well as the chiefly Notogeic ones were both descendents of an original stock inhabiting the Paleantartic region (C.G. Froehlich, 1967).

However it is very difficult to erect hypothesis on the degree of relationship between the different genera of Geoplanidae on account of the poor state of knowledge of probably more primitive key "genera" as Pelmatoplana and Coenoplana.

The chiefly Oriental Pelmatoplana, a clear hodge-podge, with rhynchodemid, bipallid and geoplanid-like species was transferred by Beauchamp (1961) to family Rhynchodemidae almost without comments. The "genus" need a thorough critical revision as regards copulatory apparatus, position of efferent system and musculature.

The hard task of studying and clearly defining Coenoplana and closely related forms, very important as regards muscle patterns besides other characters, has been taken up by Dr. Leigh Winsor of Queensland, Austrália (L. Winsor, 1977).

Kontikia and perhaps Artioposthia, also being worked by Dr. Leigh Winsor, are alone in having weak cutaneous musculature combined with a ring of parenchymal longitudinal musculature, a condition that approaches the one considered the most primitive in the Terricola.

The chief difficulty in judging these problems besides scarcity of data remains in the lack of a clear understanding of what characters are to be considered plesiomorphic, apomorphic or convergent in the Terricola. 
Timyma juliae sp. nov.

(Figs. 10-17.23 and 72-74)

Type material

Holotype: logitudinal sections of the pharynx and of the ocpulatory apparatus on 5 slides; frontal sections, from the anterior tip up to near the pharynx on 5 slides; frontal sections behind copulatory apparatus up to the tip, on four slides. Paratype: longitudinal sections of a whole immature worm, on 5 slides.

\section{DISTRIBU'TION}

Fray Jorge, Provincia de Coquimbo in the Norte Chico, inside a hygrophilous cloud-forest (dominant species Aextoxicon punctatum) localized in a semi-arid region, surrounded by vegetation of steppe type. One adult specimen (holotype) and one juvenile, collected 22 May 1962.

\section{DESCRITPION}

Small worms ending abruptly at the anterior extremity with almost the same maximum body width, so that the extremity has the form of a slightly convex spatula, and tapering posteriorly to a blunt end (Fig. 10). The maximum width of the largest specimen is $1,9 \mathrm{~mm}$, at $0,6 \mathrm{~mm}$ behind the anterior end.

Measurements:

$\begin{array}{lccccc} & \text { Lenght } & \text { Width } & \text { Height } & \text { Mouth } & \text { Gonopore } \\ \text { Holotype } & 11 & 1,9 & 1,2 & 5,8 & 7,7 \\ \text { Paratype } & 6 & 1,9 & 0,75 & 2,2 & -\end{array}$

Dorsal surface with a large band of greyish dark brown pigment (Fig. 3). It follows, at each side, a narrow ferruginous-brown band and finally, at the body margins, a brown stripe which extends a little to the ventral surface. Each ferruginous band tapers to the posterior end uniting to follow the contour of the tip. At the anterior end the ferruginous bands and the marginal stripes end abruptly without bordering the extremity, so reinforcing the appearence of a fragmented specimen. The dirty-white ventral surface has medially to the brown margins a ferruginous stripe.

The eyes (Fig. 11 and 72) in a single file around the anterior end where they mesure $40 \mu \mathrm{m} \times 27 \mu \mathrm{m}$, immediatly behind, crowded at the brown margins, surrounded by small light halos. 
The sensory border, roughly horseshoe-shaped (Fig. 12), begins at the cephalic end and proceeds narrowing progressively at each side, up to $1,3 \mathrm{~mm}$ behind in the holotype. In transverse sections up to $50 \mu \mathrm{m}$ behind the tip, the sensory border is continuous (Fig. 72), the maximum width from side to side being $500 \mu \mathrm{m}$. In the following transverse sections, through the horseshoe arms (Fig. 73), the maximum width at each side is $160 \mu \mathrm{m}$. The sensory pits are funnel-shaped, laterally compressed and antero-posteriorly elongated. The funnel tube is sub-epidermic, the remaining portion epidermic. In transverse sections the sensory border appears with a saw-like edge, as it passes through different levels of several pits, the more mesially located, being the more anterior. The elongated epidermic portion of the pit extends for up to 8 successive sections $(6 \mu \mathrm{m})$. As the sensory border narrows posteriorly, at the margins, the pits become less numerous and farther apart. Two pits measured are $48 \mu \mathrm{m}$ long, $14 \mu \mathrm{m}$ wide and $20 \mu \mathrm{m}$ deep.

The epidermis is considerably thinner in the sensory border, where it is only 5 to $6 \mu \mathrm{m}$ thick. (Fig. 74). It is there infranucleated with short, strongly cyanophilous cilia.

The dorsal epidermis is thickly beset with rhammites and chondrocysts, the latter, concentrated on 'both sides of the body, being up to $27 \mu \mathrm{m}$ high. On the ventral surface the epidermis is about half as tall, and the rhammites and the rare chondrocysts are confined to a narrow band that follows immediately internally to the sensory bor. der, between it and the creeping sole. Cyanophilous and eosinophilous glands are scanty on the whole of the ventral surface. The cilia, present all over the body, are longest, up to $6 \mu \mathrm{m}$ high, on the ventral surface. The basement membrane is thick.

The rather weak cutaneous musculature has the usual layers. It measures in two worms:

$\begin{array}{lccc} & \begin{array}{c}\text { D.C.M. height } \\ \text { in } \mu \mathrm{m}\end{array} & \text { V.C.M. height } & \text { mc:h } \\ \text { Holotype } & 13,3 & \text { in } \mu \mathrm{m} & \\ \text { Paratype } & 13,2 & 26,6 & 6 \% \\ & & 20,0 & 4 \%\end{array}$

Pharynx of simple cylindrical type (Fig. 14) with strong external and internal musculature. The external epithelium is ciliated and pierced, especially at the tip, by abundant cyanophilous and eosinophilous glands. The pharynx pocket presents a dorso-posterior diverticle that extends as far as the rear end squeezing between the copulatory complex and the dorsal body wall, then dilating considerably before introducing itself between the posterior arms of intestine, where it runs as a narrow tube. Both specimens present this unusual extension of the pharyngeal pocket. The epithelium lining the pocket is cubic and has a variable height. Restricted to the portion occupied by the pharynx, there are a circular musculature and eosinophilous glands traversing the epithelium. 
The paratype lacks ovaries and testes.

In the holotype the ovaries are situated $2 \mathrm{~mm}$ from the anterior margin. The oviducts leave the right ovary ventrally and the left one laterally to the left. Both are packed with sperm near the outlet and present small dorsal diverticles, primordia of the vitellaric funnels. The vitellaria, are not discernible.

The testes begin ventrally, nearly level with the ovaries, directly connected with the efferent ducts, running above the ventral nervous system.

Behind the last follicle, little beyond the pharyngeal root, the efferent ducts widen and become ciliated. Between the pharynx and the copulatory apparatus they are filled with sperm behaving as seminal vesicles. They run up to the muscle coat of the male atrium then curves dorsally and anteriorly to enter into short, somewhat rounded diverticles of the prostatic vesicle. The vesicle is U-shaped, with the descending arm, external to the muscle coat of the atrium, beginning dorsally at the junction of both diverticles. At the beginning of the ascending arm the vesicle enters the muscle coat and narrows considerably before penetrating entally into the male atrium. The vesicle is clothed with a high cuboidal, unciliated epithelium overlain by a very thin muscle coat. The portion of the vesicle external to the muscle coat is richly supplied with glands of eosinophilous granular secretion, being thus in fact a prostatic vesicle, the remaining portion functioning as the ejaculatory duct. The ental larger part of the male atrium has a thick, strong muscle coat. A true penial papilla is lacking, but the wall of the atrium presents 2 complex folds that are probably the functional penis. The following portion of the male atrium, devoid of folds and of muscle coat, at least ventrally, is o much smaller than the former. The ental portion is lined with a high clavate epithelium, and the ectal with a lower, cuboidal one.

From the small common atrium issues, ventrally, the gonopore canal and posteriorly the female atrium, an ascending cavity, tapering dorsally and entaly. All this portion of the atrial cavity, behind the male atrium, is clothed with a cylindrical epithelium progressively higher towards the ental narrowed extremity of the female atrium so that the atrial lumen is there restricted to a narrow canal. A kind of "ootype" a small cavity formed by the fusion of the widened ectal parts of both oviducts communicates with this canal. I is encircled by the shell glands. In longitudinal median section the "ootype" lumen plus the atrial canal are anchor shaped. The oviducts ascend bending medially, laterally to the female atrium, and dorsally to it unite to form the "ootype"

Remarkable features of Timyma juliae are the abnormal extension of the pharyngeal pocket and the "ootype"

Liana, gen. nov.

\section{DIAGNOSIS}

Geoplanidae with elongated body and broad creeping sole, of more than half the body width. Longitudinal cutaneous musculature strong dorsally and weak ventrally, where it has a portion sunk into the parenchyma, internally to the cutaneous 
nerve net. Sensory border, ventro-lateral in position, with rare minute sensory pits, restricted to the anterior tip. Testes dorsal. Adhesive glandulo-muscular organs absent. Copulatory apparatus without adenodactyls.

Type species:

Liana guasa sp. nov.

\section{DISCUSSION}

Broad creeping sole associated to numerous eyes is a feature diagnostic of Geoplanidae, among which there are four genera with a well developed system of longitudinal parenchymal musculature: Artioposthia Graff 1899, Kontikia Froehlich 1955, Choeradoplana Graff 1899 e Gusana gen. nov..

Describing the parenchymal musculature of Artioposthia Graff (1899; p. 79) says that, although a little stronger, it is similar to that of the broad and flat species of Geoplana, and further (pg. 83) that it is very strong, although not forming definite bundles in none direction.

Sections of $A$. dimenensis (Table XXXIII, fig. 5 and Table XXXIV, fig. 3) figured by him, really show a very strong parenchymal musculature, especially the lontudinal fibres, a condition never found by me in any Geoplana species.

I have sectioned, both transversally and longitudinally, two specimens of Arthoposthia sp. handed over to me by Mrs. Marion Fyfe, in order to study the parenchymal musculature.

I sent one of the sectioned specimens together with an entire worm to Dr. Leigh Winsor. They were determined by him as pertaining to a MS new species of Mrs. Fyfe still unpublished. Its parenchymal musculature is very strong consisting of a massive layer, thicker ventrally, of parenchymal musculature, that forms a ring, in transverse sections, encircling all the internal organs. It fills up nearly all the space between them and the body wall. Dorsally it consists mainly of longitudinal fibres running among transverse and diagonal fibres. Ventrally, the fibres are almost only longitudinal. However, I have seen nowhere fibres entering the parenchyma from the longitudinal cutaneous layer.

In Kontikya, Oriental in origin, the parenchymal musculature also forms a tube, consisting to interlacing transversal, diagonal and longitudinal fibres that encloses the internal organs (C.G. Froehlich, 1955, pag. 203). The longitudinal fibres aggregate in small bundles and are not derived from the longitudinal cutaneous layer.

Choeradoplana and Gusana, Neotropical genera, with dorsal testes as Liana, also have bundles of longitudinal parenchymal musculature arising from the longitudinal cutaneous layer. In Gusana the longitudinal bundles are much weaker than in Liana, more spaced, and occur both ventrally and dorsally. In Choeradoplana the deepening of the longitudinal cutaneous fibres into the parenchyma is only ventral as in Liana and originates bundles of comparable strength. Also similar in the two genera is the great development of the dorsal longitudinal cutaneous muscles. The chief diagnostic 
character of Choeradoplana are the paired musculo-glandular organs of the anterior extremity to which are related as protractor and retractor, respectivelly, the dorsal longitudinal cutaneous muscles and the ventral parenchymal ones. Both in Gusana and Liana I was unable to find any anterior specialization of the longitudinal parenchymal musculature, the fibres seem simply to disapear progressively towards the anterior end. The dorsal cutaneous musculature of Liana also does not show any anterior specialization but the muscle fibres are clearly seen bending to the external surface to end on the basement membrane. More material would neverthless be necessary for a more detailed anatomical study, using selective staining methods for muscle tissue. Before this and not knowing the behaviour of the living worm any function and biological role attributed to this pattern of musculature would be merely speculative.

From Gusana, Liana is readly separable by the simple sensory border.

Liana guasa, sp. nov.

(Figs. 19-22, 24 and 75-76)

Type material

Holotype - sagittal sections of pharynx and copulatory apparatus on 7 slides; sagittal sections of the anterior end on 8 slides; remainder portion in alcohol. Paratypes: sagittal sections of pharynx and copulatory apparatus of specimen on 12 slides, remainder in alcohol; 17 slides with transversal sections of the anterior end, from the tip up to the pharynx and 5 slides with sagittal sections of the pharynx of another specimen.

\section{DISTRIBUTION}

Nahuelbuta, Provincia Malleco, with Notophagus and Araucaria araucana as dominant plant species. Two immature specimens and another with copulatory apparatus still incompletely ripe, in December 1961.

\section{DESCRITPION}

Relatively small worms with body highly convex above and sharp margins (Fig. 19). Cephalic extremity tapering gradually to the markedly blunt tip; caudal extremity pointed and more rapidly narrowed. The two bigger worms very coiled. 
Measurements:

$\begin{array}{lccc} & \text { Length } & \text { Width } & \text { Mouth } \\ \text { Holotype } & 30,0 & 5,0 & 19,0 \\ \text { Paratype 1 } & 24,0 & 5,0 & 15,0 \\ \text { Paratype 2 } & 21,0 & 3,2 & 14,0\end{array}$

The three worms without gonopore.

Dorsal ground colour very pale grey in the smaller specimen, straw yellow in the bigger ones. On the ground a dark brown to black pigment seems to be arranged in two layers. In the lower one, it forms speckles of variable shape and intensity, and in the overlaying one, longitudinal stripes, now straight, now sinuous, with fading limits and variable intensity (Fig. 20). Along the dorsal median line this pigment, heavily concentrated, forms a narrow band that tapers towards both extremities. In the smaller worm this band ends $4 \mathrm{~mm}$ before the tip. Near the body margins both the lontidudinal stripes and the speckles are all very close, outlining a darker sub-marginal band. In the youngst worm they outline a sub-marginal and a marginal band, in the other two the ground colour appears freely at the margins. On the ventral side the dark pigment also forms irregular stripes but paler and well apart.

Around the anterior end the eyes are uniserial and quite bigger (Fig. 21); backward they form two alternate series. All along the body they are latero-ventral in position.

Dorsal and ventral epidermis richly supplied with cyanophilous and erythrophilous glands. Rhammites are very abundant dorsally, specially on the sharp edges of the body; fewer ventrally, they occur along with small rhabdites. The secretion of both types of glands plus rhabdoids form a thick layer outside the epidermis. This layer obscures the general colour pattern, and had to be removed locally on the unsectioned worm in order to expose the coloration.

The dorsal longitudinal cutaneous musculature is specially strong on the dorsal side (Fig. 75); ventrally where it is weaker, that is, the bundles of fibres are lower than the dorsal ones, it deepens into the parenchyma, between the cutaneous nerve system and the ventral nerve plate. In sagittal sections fibres could be seen, crossing the cutaneous nerve net to penetrate into the parenchyma (Figs. 24 and 76). There, in a transverse section, beginning at the ventral side, the following arrangement of the musculature is observed: a layer of fibres obliquely oriented to the right and to the left, forming a lace inside which the longitudinal bundles, consisting of a variable number of fibres, could be seen; a somewhat dense layer of longitudinal fibres that do not form definit longitudinal bundles, close to the ventral nerve plate; then between the ventral nervous system and the intestine, a layer of transverse fibres; dorsally to the intestine another layer of transverse fibres and finally, between this one and the cutaneous nerve net, a dense layer of diagonal fibres. 
Between the intestine diverticles there are bundles of dorsi-ventral fibres.

All the fibres have a light core with the contractile substance at the periphery.

In the youngst specimen, transversally sectioned from the anterior tip up to the pharynx, the cutaneous musculature is, at the level of pharynx, $120 \mu \mathrm{m}$ thick dorsally and $64 \mu \mathrm{m}$ ventrally. The height of the worm at the same level is $1,6 \mathrm{~mm}$ and the $\mathrm{mc}: \mathrm{h}=10 \%$. At the anterior end, the dorsal longitudinal cutaneous fibres bend dorsally to end on the basement membrane. Laterally, towards the ventral sensory border the cutaneous musculature progressively loses height becoming minimal if not absent. Ventrally it regains height towards the median line, attaining a little more than half the height of the dorsal portion. Nearly $1 \mathrm{~mm}$ behind the tip the cutaneous layer is $80 \mu \mathrm{m}$ at the median dorsal line, $20 \mu \mathrm{m}$ on the borders and $47 \mu \mathrm{m}$ at the median ventral line. The height of the worm at this level is $1,2 \mathrm{~mm}$. The ventral longitudinal parenchymal musculature progressively disappears towards the anterior extremity. At the same time it appears there a layer of diagonal fibres interspersed with rarer and rarer longitudinal fibres. Presumably the longitudinal fibres change direction anteriorly but it cannot be discerned.

The study of the anterior arrangement of the muscle layers was also tried in sagittal secctions of the holotype but the histological conditions of none of the worms were good enough.

The sensory border following the outline of the anterior end and restricted to it, is latero - ventral in position. It has few pits, the deepest of them lower than the epidermis, and the shallowest, mere depressions, not deeper than the height of the cilia.

The plate like nervous system concentrates towards the anterior tip, acquiring a rather cylindrical shape. In a transverse section $0,613 \mathrm{~mm}$ high, and $0,2 \mathrm{~mm}$ behind the anterior tip it has a nearly circular outline and is $0,240 \mathrm{~mm}$ high.

Pharynx cylindrical, abundantly supplied with glands, mainly erythrophylous

The description of the compulatory apparatus is based only on the holotype. From the other two worms the smallest is completely immature, with minute dorsal testes and lacking ovaries, and the bigger has only an incipient primordium of the copulatory apparatus, the testes being still massive, without central cavities and full of spermatogonia.

The ovaries were not seen, probably because they are localized behind the anterior region removed and sectioned sagitally. Vitellaria wanting.

Copulatory apparatus (Fig. 22) still without connection with the remaining portions of the reproductive system, neither efferent ducts nor oviducts could be seen. The vesicle is a long tube running almost straightly up to the penial bulb. At its ental, slightly dilated portion the vesicle presents irregular diverticles forming small canals. On reaching the bulb the vesicle continues as the ejaculatory duct moderately sinuous, that opens at the middle of the ectal face of the penial papilla. The papilla is somewhat quadrangular in sagittal section and does not reach the gonopore. The small female atrium narrows entally into a short canal slightly inclined to the venter, at the level of half the body height. All tissues are incipiently differenciated with the nuclei very numerous and concentrated. The ental half of the gonopore canal is open, but the ectal one that seems to be formed by an invagination of the epidermis is just outlined. 
Geoplana Fritz Müller

Geoplana ruca (Marcus, 1954)

(Figs. 25 - 28 and 77)

Microplana ruca Marcus, 1954, pg. 50.

Geoplana lata C.G. Froehlich, 1967, p. 160 (non Graff 1899, p. 320).

Type material

Zoological Museum, University of Lund, Sweden. One specimen.

Plesiotypes - Sagittal sections of the pharynx and copulatory apparatus on 5 slides and transverse sections anterior to the pharynx on 2 slides, of one specimen; remainder portion in alcohol. Two slides with sagittal sections of pharynx and copulatory apparatus of another specimen; remainder of the worm in alcohol. Five slides with sagittal sections of the whole body of a third specimen.

\section{MATERIAL EXAMINED}

Plesiotypes - Sagittal sections of the pharynx and copulatory apparatus on 5 slides and transverse sections anterior to the pharynx on 2 slides, of one specimen; remainder portion in alcohol. Two slides with sagittal sections of pharynx and copulatory apparatus of another specimen; remainder of the worm in alcohol. Five slides with sagittal sections of the whole body of a third specimen.

\section{DISTRIBUTION}

Lake Todos los Santos - Province of Llanquihue, type locality, one specimen. Nahuelbuta, Provincia Malleco, 15 December 1961, 1 specimen and 16 December 2 specimens. This province consists of temperate hygrophilous forests with Notophagus and Araucaria araucana as dominant trees.

\section{MEASUREMENTS}

$\begin{array}{lccccc}\text { Length } & \text { Width } & \text { Mouth } & \text { Gonopore } & \text { Creeping-sole } & \text { Height } \\ 9,5 & 2,7 & 4,3 & 2,8 & 1,2 & 1,0 \\ 9,2 & 1,9 & 4,3 & 2,9 & 0,9 & 0,7 \\ 8 & 2 & - & - & - & -\end{array}$

The dark brown back results from the superposition of 2 layers, one of brown pigment less concentrated and another of heavy concentrated black pigment. Circling the anterior extremity there is a pale yellow line bordered maginally by a dark stripe. 
The anterior extremity also has a median pale yellow line that dies out $1 \mathrm{~mm}$ behind the tip. In the smallest specimen, devoid of the median anterior line, the yellow line, followed marginally by the dark stripe, runs nearly as far as the posterior end, although disguised with a greyish pigment shortly behind the pharynx. The dorsal dark colour extends onto a ventral band, very dark at the margins but fading medially. It follows medially a yellow band with half the width of the first and finally, the yellow creeping sole bordered with brown pigment.

Eyes in a single file, restricted to the dark margins, surrounded by small light halos, and better visible in the anterior extremity (Fig. 25).

De cutaneous musculature with the three usual layers. The longitudinal layer, however, presents a few fibres immediatly inwards the diagonal layers followed by a thin layer of parenchyma, then by a second set of more numerous fibres, immediatly outside the cutaneous nerve plexus (Fig. 71). The longitudinal bundles are larger at the ventral than at the dorsal side. Also the divisions in two layers is more distinct at the venter. In the smallest specimen it is virtually inexistent.

The cylindrical pharynx with the longitudinal axis directed donwards, is very close to the copulatory organs.

None of the worms are completely ripe. The shell glands are abundant in the larger specimen and numerous in the smaller, but vitellaria are still juvenile in both worms.

Teste dorsal and intersticial to the intestine diverticles. Follicles still present in transverse sections through the pharynx of smallest specimen.

The anatomy of copulatory apparatus is well studied, so I just enumerate the most outstanding morphological features:

1) Ental portion of prostatic vesicle, the only portion external to the common muscular coat, receiving the efferent ducts and the richly ramified ducts of a tubulous gland, cyanophilous in the larger specimen and rather erythrophilous in the smallest one;

2) Well defined and always present atrial folds separating two male cavities: an ental smaller one, containing the small penis papilla, and an ectal larger one;

3) Shell glands arriving into a large cavity situated between the common oviduct and the female atrium;

4) Female atrium dislocated to the right side, opening laterally into the common atrium.

\section{DISCUSSION}

The colour pattern of the three specimens is the same as that of Microplana ruca Marcus. The width of the creeping sole (rare in Geoplanidae) is also the same in my specimens as well as Marcus's. Both materials also agree in size and general body shape. 
They come from two provinces about $400 \mathrm{Km}$ apart, with the same floristic characteristics that is, hygrophilous temperate forest.

From the internal anatomy, the copulatory complex, with very peculiar characteristics for Geoplana, is very coincident in all the worms. Among these characteristics the most remarkable is the gland of the prostatic vesicle, a complex, pluricelular structure, with ducts that have walls of their own (Marcus, p. 107; fig. 80).

In drawing the copulatory apparatus of Microplana ruca Marcus represents the prostatic vesicle outside the common muscular coat, with a relative larger extension than that of present specimens; however, in the face of all the other concordant features, these aspects, otherwise diagnostic, lose their value.

The holotype is $14 \mathrm{~mm}$ long and was reported by Marcus as "Ein Bruchstück ohne Vorderteil, Augen und Pharynx" The absence of eyes that was taken as indicative of its presence only in the anterior end, a condition exclusive of the Rhynchodemidae, could be explained by the extreme darkness of the pigment that renders frequently difficult, even with strong light, its observation. On the other hand the absence of pharynx, in a fragment $14 \mathrm{~mm}$ long, considering that worms 9,2 and $9,5 \mathrm{~mm}$ long are nearly ripe, is hard to explain.

In all the specimen here studied the pharyngeal pocket is contiguous to the ental gland of the prostatic vesicle and it would be very difficult to remove the pharynx without removing also a part of the copulatory apparatus.

The dorsal testes that were not seen by Marcus, as they extend as far as the level of pharynx only, are decisive to allocate the species to Geoplanidae. Among geoplanids it no doubt belongs to Geoplana (C.G. Froehlich, 1955, p. 16). The relatively small width of the creeping sole is rare in Geoplana although still inside the limits indicated by Graff for the genus: up to $1 / 3$ the total width of the ventral surface.

The longitudinal parenchymal musculature of the original description must be identified to the inner portion of the longitudinal cutaneous musculature.

Geoplana lata Graff only konwn through the external anatomy is very similar to $G$. ruca in shape, colour pattern and width of the creeping sole. The provenance, Corral near Valdivia, is intermediate between the original locality of $G$. ruca and that of the present material and has the same floristic aspects. However the arrangement of the dark pigment into five longitudinal stripes, one of which middorsal, differs much from what occurs in $G$. ruca.

It is believable that $G$. lata and $G$. ruca belong to the same species as they were considered by C.G. Froehlich $(1967$, p. 160$)$. Nevertheless I prefer to mantain them apart until ampler material make it possible to decide with certainty.

Consequently, as the internal anatomy of $G$. lata is not konown and as G. cruciata was transfered to a new genus, $G$. ruca stands alone in the group outlined by the cited author.

Geoplana chilensis Graff

(Figs. 20-31 and 34-35)

Geoplana chilensis Graff 1899, p. 332. 
Type material

Localization unknown.

\section{MATERIAL EXAMINED}

Four slides with sagittal sections of the copulatory apparatus, 2 slides with sagittal sections of pharynx and 1 slide of prepharyngeal transverse sections of a specimen; the remainder portion in alcohol. Sagittal sections of the copulatory apparatus, on three slides and prepharyngeal transverse sections on 2 slides of another specimen; the remainder in alcohol. Two whole worms in alcohol, one of which juvenile.

\section{DISTRIBUTION}

Palmas de Cocalán, relictic wood of palm tree Tubaea chilensis, near Santiago: 1 juvenile specimen, 5 August 1961 and 3 ripe worms, 6 September 1962. The original material had two provenances: 1 specimen from Coyinhue, near Valdivia, and 17 specimens from Santiago.

\section{DESCRIPTION}

Long worms with margins parallel along the grater part of the body relatively flattened in cross-section (Fig. 29). The anterior tapering is gradual and the end is blunt; the posterior one is abrupt and the end more pointed.

\section{MEASUREMENTS}

$\begin{array}{ccccc}\text { Length } & \text { Width } & \text { Height } & \text { Mouth } & \text { Gonopore } \\ 74 & 5 & 1,4 & 46 & 57 \\ 56 & 5 & 1,0 & 34,7 & 41,7 \\ 40 & 3 & - & - & -\end{array}$

The worms, the bigger excepted, have along the back a median light stripe, slightly wider over the pharynx and copulatory regions (Fig. 30). In all the worms the intensity of the dorsal colour depends on the concentration of the pigment, that varies between several tints of brown, being more ochraceous or more reddish. The bigger specimen, at naked eye is finely dotted of reddish brown pigment, with the dots more concentrated near the margins and along the median line. The margins are light, pigmen- 
tless (Fig. 30). Ventral side greyish. In the other specimens the pigment is more concentrated, not appearing as isolated dots; even more concentrated towards the margins where it forms a sharp limit. Marginally there is narrow, pale, reddish brown stripe that extends ventrally in one of the specimens. The ventral side of all these worms is of a very light tint of brown. 31).

Eyes arranged as a single row on the external limit of marginal light stripe (Fig.

More than $2 / 3$ on the worm height are occupied by the diverticles of the intestine. There is left almost no place for the parenchyma, specially in the bigger specimen, where the ventral nerve plate could only be discerned, lying tight between the intestinal diverticles, the completely ripe vitellaria and the bundles of cyanophilous glands.

The dorsal epithelium is packed with rhabdites specially on the sides of the body. Only the epithelium of the sole, that extends for the whole ventral width, is ciliated.

The cutaneous musculature is very weak, $16,6 \mu \mathrm{m}$ high as dorsally as ventrally. The mc:h index of the biggest specimen being equal to $2,3 \%$.

The parenchymal musculature is also weak. There are only visible some transverse fibres, specially over the intestine and some dorsiventral ones.

The pharynx (Fig. 34) is a long cylinder that may extend beyond the mouth, occupying the entire pocket, or may end level to the mouth living free a little less than $1 / 3$ the pocket lenght. The epidermis is thickely penetrated by erythrophilous glands, the cyanophilous being less numerous.

The testes were seen only in the smaller sectioned specimen, although they were looked over in sections of comparable and even anterior levels of the bigger specimen. They are uniserial, localized between the intestinal diverticles in the upper body half and end somewhat before the pharynx.

Vitellaria ripe, specially in the bigger specimen.

Efferent ducts running mesially to the oviducts. After the pharynx they are tortuous, irregularly dilated by masses of spermatozoa (Fig. 35). They extends beyond the ental extremity of the prostatic vesicle, then ascend and turn anteriorly before entering the long paired diverticles of the vesicle. The vesicle is a thick and sinuous tube. After the junction of both diverticles it dilates more and takes an upwards course, then, narrowed, it turns downwards and penetrates the common muscle coat of the copulatory apparatus. Within the coat it runs dorsally again, as far as the upper limit of the copulatory apparatus, then anteriorly and ventrally. The following final portion is considerably narrower and binds anteriorly in bigger specimen (Fig. 35) but dorsally in the smaller one, so that in this worm, its opening into the atrium is more dorsal. The lining of the whole vesicle, paired and umpaired portions, externally as well as internally to the muscle coat, is the same: an irregular cylindric epithelium. Also along the entire course, the vesicle lumen is full of eosinophilous secretion.

The common muscle coat is sharply delimited from the parenchyma and extends to the proximities of the gonopore. Besides the atrial walls are provided with a strong musculature continuous through the male and female parts. The ental half of the male atrium is greatly folded and clothed with a tall cuboidal epithelium presenting the free border strongly cyanophilous. Along the remainig antrum, ectal male half and female portion, the lining is considerably taller but the free cell borders remain cyanophilous. 
In both worms there is a large spermatophore attached to the atrial wall through a mass of strongly erythrophilous secretion, provided by the prostatic glands. The spermatophore of the bigger worm has nearly twice the size as that of the smaller one. A little beyond the gonopore, the female atrial cavity narrows dorsally passing to the wide common glandular duct, slightly inclined to the ventral side. The oviducts ascend slanted mesially, nearly up to half the body height, when they unite as the common glandular duct. The more mesial parts of the oviducts also function as glandular ducts.

\section{DISCUSSION}

The external features of the present material are well concordant with those indicated by Graff for the original material (Graff 1899, p. 332-333). Graff did not study the intemal anatomy of his specimens. The locality of the 17 specimens collected by Plate lies in the same general area, viz. Santiago; the locality of the remaining worm, Valdivia, is more distant although not incompatible.

Part of the material of $G$. nephelis Graff, not G. nephelis Fritz Müller (C.G. Froehlich 1959, p. 236-237), coming from Valparaiso, is similar, regarding shape and colour pattern, to $G$. chilensis; the distribution of the eyes was reported by Graff, as being equal to that of Coenoplana graffi C.G. Froehlich (a.c.), but it is inconsistent with that of $G$. chilensis

The internal anatomy of $G$. chilensis supports the assignement of this species to the G. pasipha group by C.G. Froehlich (1957, p. 159). G. rosea, a brazilian species belonging to the same group is of similar shape and colour pattern, nevertheless the eyes are widespread throughout the back and the pharynx is collar shaped, besides being different in the details of the copulatory complex. The same holds true for $G$. plana, another Brazilian species of the same group, superficially similar to $G$. chilensis.

Geoplana ercilla sp. nov.

(Figs. 32-33, 36-39 and 40-44)

Type material

Holotype sets.of sagittal sections through the pharynx and copulatory apparatus, on 8 slides; prepharyngeal transverse sections on 6 slides; the remaining in alcohol. Paratype 7 slides with sagittal sections from the pharynx and copulatory apparatus; remaining in alcohol.

\section{DISTRIBUTION}

Nahuelbuta, Provincia Malleco; dominant trees Notophagus and Araucaria araucana; 2 specimens, December 1961. 


\section{DESCRITPION}

Small worms with the body gradually narrowing towards the anterior blunt extremity and abruptly to the posterior pointed one (Fig. 36). The cross section has a peculiar shape: the nearly flat back is sharply separated from the convex ventral side, that comprehends the lateral sides of the section, with the same characteristics of the back, and the sole. The sides are $1 / 4$ the sole width, have the same colour and rhabditoids as the dorsal side, as well as eyes.

Under the stereomicroscope the back and the sides, speckled with dark brown to black pigment, have a fine marbled appearence. A median longitudinal line is outlined through a heavier concentration of the dark spots (Fig. 32). There is a lighter patch over the pharynx. The sole is also speckled with brown, although much paler and also has a median ventral line of more concentrated spots.

\section{MEASUREMENTS:}

$\begin{array}{cccccc}\text { Length } & \text { Width } & \text { Height } & \text { Mouth } & \text { Gonopore } & \text { Sole } \\ 17,0 & 3,8 & 1,2 & 6,0 & 5,0 & 2,2 \\ 19,0 & 3,8 & 1,2 & 5,4 & - & -\end{array}$

At the very anterior tip there are eyes in a marginal file and a few more ventrally. Immediatly behind, they begin to increase progressively in numbers spreading over almost all the back and even lateroventrally, in the centre of small light halos, so crowded at some points to become confluent (Fig. 38). One of the specimens has the dorsal eyes spread to about $1,5 \mathrm{~mm}$ on each side (Fig. 32), besides the lateroventral ones (Fig. 33).

Dorsal epithelium with cyanophilous and eosinophilous glands and rhabdoids mostly of rhammite type. The dark pigment extends from the basement membrane up to the internal limit of the cutaneous musculature. Ventral epithelium with cyanophilous glands and rare eosinophilous ones; rare small rhabdites.

Longitudinal cutaneous musculature very strong, with tall, narrow and compact bundles. In the youngst specimen, $2 \mathrm{~mm}$ anterior to the pharynx, it is $120 \mu \mathrm{m}$ high at the dorsal and $146 \mu \mathrm{m}$ at the ventral side; in the bigger one, nearly $1,5 \mathrm{~mm}$ before the pharynx, it is $146 \mu \mathrm{m}$ and $133 \mu \mathrm{m}$ high respectively at the dorsal and the ventral sides. The mc: $h$ index of both specimens is, respectively, $22 \%$ and $23 \%$.

Parenchymal transverse musculature thick, forming a sharply delimited layer of muscle bundles, especially below the intestine. In the bigger specimen, about $4 \mathrm{~mm}$ before the pharynx, the bundles are 65 to $105 \mu \mathrm{m}$ high and 27 to $40 \mu \mathrm{m}$ wide. In the smaller one, about $4 \mathrm{~mm}$ before the pharynx, the average height of the dorsal and ventral bundles is, respectively, 47 and $57 \mu \mathrm{m}$. The fibres of the sub-intestinal layer spread laterally, ending on the surface epithelium, from the venter up to the dorsal side. 
The parenchymal dorsoventral musculature also forms strong bundles, specially on the sides of the body where they are obliquely directed from the back to the ventrolateral surface.

On account of the great development of the longitudinal cutaneous muscles, the cutaneous nerve system lays so close to the ventral nerve plate that they became mixed up at certain points (Fig. 43).

The parenchyma is loose.

The pharynx is everted in both specimens. It is a tube abundantly provided with cyanophilous glands and with a smaller number of erythrophilous ones.

Both specimens are still young, the smaller one has not even opened the gonopore. On the transverse sections both efferent ducts and ovicucts were not seen.

The dorsal, numerous testes extends nearly up to the pharynx root. They are still massive, full of spermatogonia and spermatid.

On both specimens the copulatory apparatus (Figs. 41-42) have incompletely differencitated tissues.

Immediatly behind the pharynx pocket the efferent male canals, coming from the sides, ascend nearly up to half the body height where they unite into a single duct. The latter keeps ascending almost attaining the upper level of the copulatory apparatus. At this point, narrowed, it bends posteriorly and proceeds horizontally to open into the bottom of a dorsal atrial fold. As I was not able to discern the efferent ducts on the transverse sections and the male canals begin in the neighbourhood of the copulatory apparatus the latter must be considered as paired diverticles of the prostatic vesicle. The atrium presents dorsally and laterally several complex folds, ventrally the wall is smooth. The whole atrial wall is clothed with a flat epithelium. Opening on the surface of the atrial folds there are innumerable structures similar to those described by. Furhman in $G$. vongunteni Furhman. They are short, narrow blind ended canals, sunk into the atrial surface. Cross sectioned they appear as circular structures presenting around the epithelium lining, still incompletely differenciated, a pinkish layer that could be a developing sphincter, as those presented by $G$. vongunteni. Surrounding the pinkish layer there are nuclei in a concentric arrangement. The diameter of several such structures was determined, measured from the periphery of concentric nuclei, and the average value is $100 \mu \mathrm{m}$. In the bigger specimen some of them attain $160 \mu \mathrm{m}$. There is not any differenciated muscles and not even primordia of glands.

\section{DISCUSSION}

It is well known that the shape of transverse section depends greatly on the amount of movement (Fyfe, 1946; pág. 137) and on fixation, that is, in both cases on the degree of muscle contration (Du B-R. Marcus, 1957; pag. 161). Nevertheless, in G. ercilla it could not be considered merely as an accident of the fixation technique. The sharp margins separating a flat dorsal surface, whose morphological characteristics extend to the lateral parts of a convex ventral surface, must be resultant of the arrangement of the ventral transverse layer of parenchymal musculature and specially of the muscles obliquely running from the dorsal to the lateroventral surface. 
In the literature of the Terricola only 3 species were drawn with flat back and convex venter: Pelmatoplana treubi Graff (1899, plate 5, fig. 14), Bipalium semperi (Graff, 1899; plate 9, fig. 3) and Rhynchodemus michaelseni Graff (1899; plate 17. fig. 32), but their internal anatomies are not known. Species with narrow creeping sole (Pelmatoplana, Rhynchodemidae and Bipaliidae) have dorsal charactheristics extending ventrolaterally, but they have rounded margins or no margins at all if they are cylindrical.

The height of the longitudinal cutaneous musculature (Fig. 43) and the mc:h index of $G$. ercilla are not common among Geoplana species. From a hundred species of Brazilian and Peruvian species, thirty were selected among those of highest cutaneous musculature and their mc:h indices were determined. Only in the ten species listed below, to which $G$. ercilla was added, the index is superior to $15 \%$.

$\begin{array}{ll}\text { G. marginata, sensu Marcus } & 16 \% \\ \text { G. pasipha } \text { Marcus } & 16 \% \\ \text { G. crioula } \text { Foehlich } & 16 \% \\ \text { G. plana } \text { Schirch } & 17 \% \\ \text { G. } \text { carinata } \text { Marcus } & 17 \% \\ \text { G. grisea } \text { Froehlich } & 17 \% \\ \text { G. goettei } \text { Froehlich } & 18 \% \\ \text { G. mülleri Froehlich } & 18 \% \\ \text { G. ita } \text { Froehlich } & 19 \% \\ \text { G. jandira } \text { Froehlich } & 22 \% \\ \text { G. ercilla } \text { sp. nov. } & 22 \% \text { to } 22 \%\end{array}$

Rarelly the parenchymal transverse musculature is so strong among Geoplana species as in G. ercilla. Generally, as in G. ercilla, the development of parenchymal musculature is directly proportional to that of the cutaneous musculature (C.G. Froehlich 1955; p. 209). Nevertheless in most species of Geoplana, the transverse musculature, even the sub-intestinal layer, generally the better developed, is not sharply delimited as the fibres are scattered or just a few gather in small bundles. In $G$. ercilla this layer (Fig. 43) is an outstanding character as it presents large massive bundles.

The ten above mentioned species, regarding several characteres, of the internal as well of the external anatomy are placed in different groups (C.G. Froehlich, 1967) in this manner evidencing the adaptative nature of the development of the cutaneous musculature.

All of them stand well apart from G. ercilla.

Despite not having attained its full development the copulatory apparatus of both worms is well enough characterised by the absence of typical penial papilla, by the 
dorsal entrance of male canal into the atrium and by the peculiar structures (glandulo-muscular?) that open in the surface of the atrial folds.

Although these structures are not completely differentiated they can be compared to the structures presented by a group of species (C.G. Froehlich, 1967, p. 158) that extends from Costa Rica to Peru and Trinidad. Its distinctive characters are the presence of a penial papilla, and the female canal horizontal or coming from the ventral side.

The female canal of $G$. ercilla is not yet visible, but the papilla would be surely present at this stage of the development of copulatory apparatus. Every time I have sectioned young worms of species provided with a penial papilla, even when they had only primordia of the copulatory apparatus, the papilla was already clearly outlined.

In the group mentioned were included $G$. vongunteni Fuhrmann, from Colombia and $G$. idaia du B-R. Marcus, from Peru.

Studying sections of the original material of $G$. idaia I verified that the penial papilla, described as oblique, could not be considered as a typical one. Lateral sagittal sections evidence that what actually exists is a large fold of the whole wall of the male atrium. In the median sections the fold only displays its continuity with the ental wall as a typical penial papilla. So $G$. idaia acquires a doubtfull situation within the $G$. gigantea group, and $G$. ercilla must to be compared to it.

The small structures opening on the atrial folds of $G$. ercilla, while incompletely developed, seems to be simpler than those of $G$. idaia and more similar, as already stated, to those of $G$. vongunteni another species belonging to the $G$. gigantea group. Regarding the musculature $G$. idaia and $G$. ercilla are very distinct, in $G$. idaia being weaker both the cutaneous and the transverse parenchymal musculature, the latter consisting of some, very sparse fibres. The $\mathrm{mc}$ :h index of $G$. idaia is $7 \%$.

As it was mentioned in the introduction $G$. ercilla was related by C. G. Froehlich to two other species for which he recomended the erection of a new genus. These two species have adenodactyls in the copulatory apparatus. The small structures of the copulatory apparatus of $G$. ercilla could well develop into adenodactyls, but in the present stage, they are much more alike to the similar structures of $G$. idaia and $G$. vongunteni. On this ground, despite the striking pecularities of shape and musculature I consider $G$. ercilla, at least tentativelly, a Geoplana.

Geoplana placilla sp. nov.

(Figs. 45-49 and 50-51)

Type material

Holotype: sagittal sections of pharynx and copulatory regions on 5 slides. Paratypes: sagittal sections of pharynx and copulatory apparatus on 8 slides; prepharyngeal and copulatory apparatus on 8 slides; prepharyngeal transverse sections on 2 slides and several fragments of about 5 specimens, in alcohol. 


\section{DISTRIBUTION}

The type locality is San Alfonso de Maipo, ca. $45 \mathrm{Km}$ SE from Santiago, Pre-Cordillera, dry savannah with Acacia caven. All the worms are fragmented, in a poor state of preservation, so it is impossible to know how many specimens there are. Collected on 1 ? May, 1961.

\section{DESCRIPTION}

Cephalic end gradually narrowed, blunt; caudal one abruptly narrowed, pointed. Two pieces seeming to belong to the same specimen, are together $22 \mathrm{~mm}$ long and the larger width, level with the pharynx, is $3 \mathrm{~mm}$. Two other fragments, apparently belonging to another specimen, are together also $22 \mathrm{~mm}$ long and $2,8 \mathrm{~mm}$ wide near the pharynx. In the first recomposed worm the mouth and the gonopore lies, respectively, $4,7 \mathrm{~mm}$ and $2,0 \mathrm{~mm}$ behind the posterior extremity; in the second one, respectively, $6,1 \mathrm{~mm}$ and $3,2 \mathrm{~mm}$.

Dark brown back with a light stripe along the median line. Heavier pigmentation along the body margins and bordering the median stripe. In the lighter band between them, the eyes could be seen largely widespread and surrounded by pigmentless halos. Milky parenchyma visible along a stripe bordering the fore end and separating dorsal and ventral colours. Ventral side greyish pale-brown, also with a median longitudinal light stripe, ending before the dark-brown cephalic extremity.

Very weak cutaneous musculature; epidermis equally high dorsally and ventrally. Parenchymal musculature also weak.

Pharynx of cylindrical type with ruffled border.

Holotype vitellaria unripe; vitellaric funnels present in sagittal sections of the pharynx and copulatory regions. Paratype vitellaria not yet discernible.

Testes large, easily visible through the ventral lighter surface of the cleared worms; more or less uniserially arranged.

Asymmetric copulatory apparatus with gonopore displaced to the left. In one of the unsectioned specimens the deviation is $0,5 \mathrm{~mm}$.

Efferent ducts entering into the prostatic vesicle laterally and considerably beyond its proximal end; in the bigger specimen nearly twice as far from this end as in smaller one. They are relatively thin with very few spermatozoa in the ectal portions.

Vesicle long, dilated at the ental extremity, weakly muscular and running nearly stright to the penial bulb. It receives delicate glands with secretion taking both stains. Within penial bulb, decreasing progressively in diameter, vesicle passes to ejaculatory duct, lined, in opposition to the vesicle, by smooth epithelium. There is in the holotype, between the final part of ejacultory duct and its ental half, a dilated portion with very thin walls.

Penial papilla also asymmetric, displaced to the left, with the tip bent to the same side. Atrium wholly filled up by the penis which is clothed with thin, pleated epithelium.

Female atrium displaced to the right and lined with a cellular mass that almost 
obliterates the narrowed ental portion, adjacent to the entrance of common glandular duct. This one, short and wide, coming dorsally from the ventral side, receiving shell glands along ascendent transverse portions.

\section{DISCUSSION}

G. placilla could be conspecific with part of the material of G. pulla (Darwin) studied by Graff (1899, p. 302 and Tafel III Figs. 1-2), since the external features of the darker specimens are similar to those of the new species. Describing the genital apparatus Graff does not refer to any asymmetry and report the penis shape as conical; besides in the drawings (p. 148 and 183) the vesicle was shown inside the penial bulb, and the atrial lining equally high through the whole cavity. However Graff's material is heterogeneous regarding the provenances (Paraguay, Argentine and Chile) and that of the anatomicaly studied worm was not indicated.

G. placilla is another species to be located in the $G$. taxiarcha-group (C.G. Froehlich, 1967, p. 158-159). Within this group it is more akin to the species with a cellular mass, of variable development, filling the female atrium. Also to this group, belongs G. pulla. The combination of external characters, and of the details of copulatory apparatus, its asymmetry being the most distinctive, separates $G$. placilla from the other components of the group.

Geoplana chanca sp. nov.

(Figs. 52-56)

Type material

Holotype sagittal sections of copulatory region on 7 slides; sagittal sections of pharynx on 4 slides; transverse sections of prepharyngeal region on 4 slides; remainder of worm in alcohol. Paratype 7 slides with sagittal sections of pharyngeal region on 4 slides; remaining parts in alcohol. Coiled worms in very ill state of conservation.

\section{DISTRIBUTION}

Typical locality Nahuelbuta, Provincia Malleco, with Notophagus and Araucaria araucana as dominant tree species. Holotype 16 and paratype 14 December 1961.

\section{DESCRIPTION}

Broad and flat species (Fig. 52) tapering a little more gradually to the fore end than to the rear one. Both extremities rather pointed. 


\section{MEASUREMENTS:}

$\begin{array}{lcccc} & \text { Lengti } & \text { Width } & \text { Mouth } & \text { Gonopore } \\ \text { Holotype } & 40,5 & 6,3 & 28,5 & 35,1 \\ \text { Paratype } & \text { ca. } 50 & \text { ca. } 7 & - & - \\ \text { Paratype } & \text { ca. } 45 & \text { ca. } 4 & - & -\end{array}$

Dimensions of paratypes approximate, since the worms are much coiled, with dorsal side strongly curved down. Besides, in the sectioned specimen the anterior tip is injured.

Dorsal side with 2 broad dark-brown bands, darker along their margins, especially the mesial ones, where they form 2 very dark para-median stripes. The intermediate lighter zone has a more olivaceous shade. Numerous pigmentless halos around the eyes contributes to the lighter shade of this zone. Along the median line there is a pale yellow stripe with a ferruginous tint limiting it against the dark stripes. Marginally a ferrunginous yellow line separates the dorsal from the ventral face. To the unaided eye the venter is pale-brown. On closer examination it presents, on each side, a marginal band mottled with brown markings becoming, at first, sparser, then, closer towards the median slightly brown line.

Eyes uniserials around anterior end begin spreading dorsally $2,9 \mathrm{~mm}$ behind the tip, occupying up to $2,5 \mathrm{~mm}$ of the total body width on each side.

Epidermis dorsally higher, packed with large rhabdites, and the ducts of cyanophilous and erythrophilous glands. Well developed glandular border.

Strong cutaneous musculature; diagonal layers rarely so thick in Geoplana. Dorsal and ventral cutaneous musculature, respectively, 99,75 $\mu \mathrm{m}$ and 199,5 $\mu \mathrm{m}$ high. Index $\mathrm{mc}: \mathrm{h} 20 \%$. Parenchymal transverse musculature equally developed supra and sub-intestinally. Diagonal and dorso-ventral musculature also well developed.

Pharynx of the bell-type (Fig. 53); in the holotype anterior insertion ventral, posterior one dorsal; both dorsal in the paratype. Muscularis, underlying the lumen epithelium, very strong. Secretion of superabundant eosinophilous glands partly filling up pharyngeal pocket. Cyanophilous glands scarce.

Teste dorsal, pluriserial, ending before the pharynx. Efferent ducts, dorsal to and a little more medial than the oviducts. Full of spermatozoa, they overpass the proximal end of vesicle, curve dorsally and open into paired diverticles of the prostatic vesicle. These are short, and curve dorsaly before uniting into the vesicle. The vesicle, dilated entally. narrows progressively towards the penial bulb. It is lined with cylindrical epithelium whose variable height diminishes ectally, and receives copious glands with fine granular, eosinophilous secretion. The long glandular ducts occupy the entire space between pharynx and penial bulb. Before penetrating the penial bulb where it becomes the ejaculatory duct, the vesicle, up to here running slightly directed to the left, bends to the right. The ejaculatory duct has a smaller diameter, no glands and a lower epithelium which gets ectally even lower. It traverses the bulb and enter 
the small conical papilla where it bends to the left before opening into a small, elongated cavity formed by invagination of the surface of the papilla. Both, the bulb and the papilla, are muscular. The short papilla ends before the gonopore and presents a dorsal fold (Fig. 56). It seems contracted as this fold does not exist in the paratype whose penis overpasses the gonopore and curves to the right side (Fig. 55). Erythrophilous glands open into the atrial cavity dorsally to the papilla and great part of the atrial lumen is filled with its fine-grained secretion. Another strongly erythrophilous glands, of coarser secretion, also open into the whole male atrium, and on the penial surface, including the invaginated portion. Cyanophilous glands begining at the penial root, as dorsally as ventrally, arrive throughout the whole atrial wall, and extend to the female atrium where they are more abundant. The female atrium is funnel-shaped with the ental straightened part, the vagina, curved dorsally. It is lined with a columnar epithelium taller entally.

The oviducts begin ascending directed mesially, before the gonopore, widening considerably along their course. Arriving to their most dorsal level, above the atrium, they tum posteriorly, widen even more, and finally enter the vagina. The shell glands open from about half way the ascending portions of the oviducts to their entrance into the vagin. Vitellaria still forming a network.

Besides the differences already noted for the penis the paratype copulatory apparatus presents the following differences: the intrabulbar course of the ejaculatory duct is quite deviated to the left, consequently the next portion is nearly transversal; the glands of the vesicle are neutrophilous and the strongly erythrophilous glands of male atrium and papilla are lacking; the oviducts bend slightly to the ventral side before their outlet in the vagina.

\section{DISCUSSION}

As the preceding species, $G$. chanca belongs to the $G$. taxiarcha-group and also approaches externally to $G$. pulla (Darwin) (Graff, 1.c.). The copulatory apparatus of the latter is more concordant with that of $G$. chanca than with that of $G$. placilla, regarding the shape of penis and the lining of the female atrium, however the position of the efferent ducts entrance into the vesicle, wrapped by a few fibres of the bulb musculature, is quite different. In $G$. placilla as in $G$. pulla the efferent ducts arrive laterally, nearly at the middle of the vesicle and in $G$. chanca entally, into ventrally curved diverticles. Dawin's material is Uruguyan, Graff had specimens from Paraguay, Argentina and Chile and one could well doubt their conspecificity. On the other hand Graff does not indicate the provenance of the pictured worm or that of the one studied anatomically. Hence, the possibility remains of $G$. chanca and at least part of Graff's $G$. pulla belonging to the same species.

G. chanca is fundamentally different from $G$. placilla by the strong cutaneous and parenchymal musculatures. G. chanca, contrary to G. placilla has a well developed glandular border, and a cylindrical pharynx, whereas the pharynx of $G$. placilla is bell-shaped. 
Geoplana tirua sp. nov.

(Figs. 57-58 and 60-62)

Type material

Holotype sagittal sections of copulatory apparatus on 5 slides; saggital sections of pharynx region on 4 slides and the remaining anterior and posterior portions in alcohol.

\section{DISTRIBUTION}

Type locality, Palmas de Cocalán, Provincia O'Higgins relict wood of Tubara chilensis. One specimen, 6 September 1962.

\section{DESCRIPTION}

Broad and flat species tapering gently to the anterior end and abruptly to the posterior one. Both extremities acutely pointed (Fig. 57). Length $50 \mathrm{~mm}$ and width, level with the mouth, $8 \mathrm{~mm}$. Mouth and gonopore respectively $29,2 \mathrm{~mm}$ and $43,1 \mathrm{~mm}$ behind anterior tip. Height, just anteriorly to pharynx, $17 \mathrm{~mm}$.

Gephalic extremity outlined by a narrow pigmentless stripe even more narrowed posteriorly, almost disappearing. On the dorsal side two straw-yellow stripes running medially with a pigmentless line between them. Following, to the sides, a dark-brown stripe, then a hand with the very light-brown pigment only appearing between the extremely numerous pigmentless halos around the eyes. Finally, at the margins, intersticial pigment, dark now, outlinig a brown stripe. Ventral side straw-yellow.

Largest eyes on the anterior end, restricted to the margins, although not in single file; widening, $7 \mathrm{~mm}$ behind, to a broad band, up to $2,5 \mathrm{~mm}$ wide; practically leaving free just the median yellow stripe.

Faulty fixation; dorsal and lateral epidermis with many large rhabdites, as far as the well developed glandular border.

Ventral epidermis with smaller rhabdites.

Weak cutaneous musculature, $91 \mu \mathrm{m}$ high ventrally and $38 \mu \mathrm{m}$ dorsally; mc:h $=9 \%$. Parenchymal musculature with normal layers, none presenting any special development.

Pharynx bell-shaped with high muscularis and plenty of erythrophilous glands. Pharyngeal pocket with a small, dorsal, posterior diverticle, lined with taller epithelium (Fig. 62).

Incompletely ripe worm. Testes dorsal, pluriserial, small, ceasing level to pharynx. Vitellaria, certainly too young, not seen.

Narrow efferent ducts widening just on entering, entally, the prostatic vesicle, where they present a mass of spermatozoa (Fig. 58). Prostatic vesicle tubular, long and straight, narrowing towards penis bulb; on penetrating the bulb it bends to the right before passing to ejaculatory duct. The latter, considerably narrower, traverses the 
papilla descending almost straightly. Penial bulb and papilla small. Atrial cavity almost entirely filled with penial papilla, narrowed and curved dorsally to constitute the vagina.

Oviducts start raising anterior to the gonopore, and increase in diameter along the ascending course. Above atrium they bend posteriorly and ventrally uniting into vagina. Shell glands still incipient, their open into female canal not visible.

\section{DISCUSSION}

G. tirua is another species to be allocated to the G. taxiarcha-group, near G. placilla and $G$. chanca. Of the three, $G$. tirua is the largest with the most abundant eyes. However it approaches more $G$. chanca, regarding external features and anatomy. The principal differences are the absence of the pharingeal pocket diverticle in $G$. chanca and of the prostatic vesicle diverticles in G. tirua. The absence of the latter could hardly be due to immaturity.

Nevertheless, decisive for separating both species is the development of cutaneous and parenchymal musculature. It suffices to compare the mc: $h$ index, respectivelly $20 \%$ and $9 \%$ in $G$. chanca and G. tirua.

Geoplana caleta sp. nov.

(Figs. 59 and 63-67)

Type material

Holotype sagittal sections of the region of pharynx and copulatory apparatus on 10 slides, remainder in alcohol. Paratypes copulatory apparatus and pharynx sections on 35 slides, remainder in alcohol; 6 ripe specimens and one juvenile in alcohol.

\section{DISTRIBUTION}

Vallenar, Province of Atacama, River Huasco bank, under stone. Hygrophilous matorral. Nine specimens, 16 August 1963.

\section{DESCRIPTION}

Broad and flat worms with anterior extremity more acute than the posterior one.

Dorsal ground color and venter light-brown. Dorsally on the ground, a fine dark-brown to black granulation aggregated into ill defined, irregular strips, creating a general marbled appearence. Along the median dorsal line a light stripe at which sides the granulation concentrates outlining 2 para-median bands in the majority of specimens. There is also a concentration of granules marginally, outlining a narrower band. 
MEASUREMENTS OF 7 SPECIMENS:

$\begin{array}{lcccc} & \text { Length } & \text { Width } & \text { Mouth } & \text { Gonopore } \\ \text { Holotype } & 30,3 & 7,8 & 18,8 & 23,3 \\ \text { Paratype } & 33 & 8 & 18 & 23 \\ \text { Paratype } & 32 & 6 & 19 & 24 \\ \text { Paratype } & 33 & 6 & 20 & 25 \\ \text { Paratype } & 37 & 7 & 22 & 28 \\ \text { Paratype } & 31 & 7 & 18 & 23 \\ \text { Paratype } & 30 & 7 & - & -\end{array}$

Eyes uniserial, with low pigment-cups, up to $2,2 \mathrm{~mm}$ from the tip; then elongated, as far as $3 \mathrm{~mm}$ from the tip. Thence forth, spread dorsally occupying ca. $2,8 \mathrm{~mm}$ on each side, they are of irregular shape, small and crowded at the margins, and larger and more scattered towards the median line.

Dorsal and ventral epidermis cilitated, traversed by cyanophilous and erythrophilous glands, the former more numerous ventrally. Dorsally, abundant rhabdites and rhammites; ventrally, small rhabdites.

Weak cutaneous musculature; parenchymal one with strong dorsi-ventral muscles and, above intestine, scattered diagonal fibres.

Cylindrical pharynx with ruffled border.

Dorsal testes very numerous; completely ripe or, seemingly, spent; ceasing level with the pharynx.

The efferent ducts form ample spermiducal vesicles and, on approaching penial bulb, are directed dorsad and mediad. At the end of this obliquely ascending course, the spermatozoa are replaced by the same eosinophilous secretion of the glands emptying into the prostatic vesicle and into the widened portion of the ejaculatory duct. Prior to their entrance into the forked ental portion of the vesicle, the ducts become considerably thinner. After the junction of both diverticles, the prostatic vesicle runs dorsad and posteriad, loosing diameter up to its entrance into the bulb, where it passes to the ejaculatory duct. The vesicle is lined with strongly eosinophilous glands. Entally, the ejaculatory duct is tortuous, clothed with a ciliated cylindric epithelium, and receives the same erythrophilous glands as the vesicle; next, there is a short widened part lined with flat epithelium devoid of cilia, and with a mass of erythrophilous secretion in the lumen; thence forward the duct is directed ventrad, without curves, lined again with cylindric ciliated epithelium. It narrows along this course bends posteriorly before opening into a reentrance of the penial surface.

The penial papilla is more or less bell-shaped with a rather irregular outline. It receives three types of glands: one, of very thin secretion taking both stains, open especially on the ventral surface; a second of strongly erythrophilous secretion open on its base; finally a third, even more strongly erythrophilous and with very close ducts, 
open in reentrances of its ventral surface. The papilla extends as far as the gonopore. The common antrum is clothed with cylindric epithelium; entally and dorsally it narrows forming the short vagina that receives the common glandular duct arriving dorsally from the anterior side. The oviducts receive the shell glands throughout its ascending course.

The vitellaria seem to be spent.

The paratype has the penial papilla curved laterally, the ejaculatory duct less tortuous, the vesicular glands with neutrophilous secretion and the third type of penial glands intensely cyanophilous instead of erythrophilous. Both specimens have the common antrum partially filled with a large mass of erythrophilous secretion, seeming to be derived. principally from the second type of glands opening on the penial surface.

\section{DISCUSSION}

$G$. caleta appears to be very close of $G$. marmorata F. Müller, as they have the same colour pattern and a very similar copulatory apparatus. However the penial papilla of $G$. marmorata has a form much less well defined than that of $G$. caleta. The latter has an irregular penial surface and in the paratype the papilla is curved laterally, but as a whole, the form is the same, there being even coincidence in the small fold at the dorsal root of both specimens. The atrium of $G$. marmorata is sensibly larger than that of $G$. caleta.

Nevertheless, the two forms are separated by strong zoogeographic barriers and it would be difficult that both could belong to the same species considering their small capacity of dispersion and their extreme dependence of humidity, unless one admits human agency in their transport. So it is preferable to mantain them separated untill more material is available.

C. G. Froehlich (1967, p. 158) included in the list of species belonging to $G_{\text {: }}$ applanata-group "three undescribed species from Chile" One of these is, without doubt, $G$. caleta, the other two may be $G$. tirua and $G$. chanca assigned by me to the $G$. taxiarcha-group. Both groups, with similar distribution and the same distinctive characters differs mostly by the average size of species and the relative body flatness, so one can expect some overlapping. $G$. caleta besides approaching anatomically $G$. marmorata, of the $G$. applanata-group is the flatest of the three species, although being the smallest (30 to $37 \times 7 \mathrm{~mm})$. G. chanca $(40 \times 6$ and $50 \times 7 \mathrm{~mm})$ approaches anatomically $G$. pulla, of the $G$. taxiarcha-group and is of similar size as $G$. pavani (40x5 or $40 \times 6 \mathrm{~mm}$ ) of the same group. Regarding the size $(50 \times 8 \mathrm{~mm})$ and the form (relatively flatter) $G$. tirua could well be placed in the $G$. applanata-group, but it is very similar to $G$. chanca as already discussed, regarding the anatomy of copulatory organs. 


\section{BIBLIOGRAFIA}

BALL, I. R. 1974 - A contribution to Phylogeny and Biogeography of the Freshwater Triclads (Phatyhelminthes: Turbellaria). In Riser N.W., \& M.P. Morse, "Libbie H. Hyman Memorial Volume Biology of Turbellaria": 339-401. McGraw Hill Book Co., New York.

BEAUCHAMP, P. de 1961 - Classe de Trubellaries, em Pierre-P. Grassé, Traité de Zoologie 4 (1): 35-212. Masson et Cie.

BOCK, J. WALTER AND GERV VON WAHLERT. 1965 - Adaptation and the form-function complex. Evolution 19 (3): 269-299.

BRESSLAU, E. 1933 - Turbellaria. W. Kukenthal \& Th. Krumbach, Handb. Zool., 2: 52-293.

DENDY, A. 1892 - On the Presence of Ciliated Pits in Australian Land Planarians. Proc. Roy Soc. Vict. 4 : 39-46.

FROEHLICH, C.G. 1955 - Sobre morfologia e taxonomia das Geoplanidae. Bol. Fac. Fil. Ciên. Letr. Zool., 19: 195-297.

FROEHLICH, C.G. 1959 - On Geoplanids from Brazil. Bol. Fac. Fil. Ciênc. Letr. Zool., 22: 201-265.

FROEHLICH, C.G. 1967 - A contribution to the Zoogeography of Neotropical Land Planarians. Acta Zool. lilloana, 23: 153-162.

FROEHLICH, E. M. 1955 - Sobre espécies brasileiras do Gênero Geoplana. Bol. Fac. Fil. Ciênc. Letr. Zool., 19: 195- 279.

FUhRMANN, O. 1914 - Planaires terrestres de Colombie. Mem. Soc. Neuchat. Sci. Nat., 5: 708-792.

GOETSCH, W. 1933 - Verbreitung und Biologie des Landplanarien Chiles. Zool. Hahrb. Syst. 64: 245-288.

GRAFF, L. VON 1899 - Monografie der Turbellarien II. Tricladida Terricola. 1: xiii + 574, 258 pls. Englemann, Leipzig.

GRAFF, L. VON 1912-1917 - Tuberllaria II. Tricladida. H.G. Bronn, Klass Ordn. Tier-Reichs., 4: 2601-3369.

HUECK, K. 1972 - As florestas da América do Sul, ecologia, composiçāo e importância econô. mica; tradução de Hans Reichardt. xii $+466 \mathrm{pp}$. Ed. Universidade de Brasilia.

MANN, G. 1960 - Regiones biogeograficas de Chile. Invest. Zool. Chil. 6: 15-49.

MARCUS, E. 1953 - Turbellaria Tricladida. Exploration du Parc National de l'Upemba, Mission G. F Witte, 1946-1949,21: 62 pp.

MARCUS, E. 1954 - Turberallaria. Reports of the Lund University Chile Expedition $1948 \quad 1949$, 11. Lunds Universitets Arsskeift, new series, $A$ vd. 2, 19 (13): 115 pp.

MARCUS, E. DU BOIS-REYMOND 1951 - On South American Geoplanids. Bol. Fac. Fil. Ciênc. Letr., 16: 21 7-255.

MEIXNER, J. 1928 - Der Genital apparat der Tricladen und seine. Bezuhungen zu ihrer allgemeinen. Morphlogie, Phylogenis, Okologie und Verbreitung. Z. Morphol Okol. Tiere, 11: 570-612. 
PRUDHOE, S. 1949 - Some Round worms and Flat worms from the West Indies and Surinan, IV. Linn. Soc. Journ. Zool., 41 (281): 420-433.

WINSOR, L. 1977 - Terrestrial Planarians and Nemerteans of the Otway Region. Proc. R. Soc. Vict. 89 (1): 137-146.

\section{LETTERING OF DETAILS ON ALL FIGURES}

$$
\text { a - male atrium }
$$

a1, a2, a3 - different sections of the atrium

ac - common atrium

b - penis bulb

bf - pharyngeal pocket

bp - atrial folds separating two atrial portions

c - mouth

ce - ejaculatory cavity

ci - cilia

de - efferent ducts

df - sensory pit diverticles

ds - ental diverticles of prostatic vesicle

e - ejaculatory duct

ep - epidermis

es - sphincter

f - female atrium

fa - pharynx

fs - sensory pit of simple type

fse - ramified sensory pit

g - gonopore

gc - glandular body

gl - glands

i - intestine

k - muscularis of pharynx

1 - ventral lateral bands morphologically similar to the back side.

$\mathrm{m}$ - muscle coat of the copulatory apparatus

ma - muscularis of the atrium

mc - cutaneous musculature

mdc - oblique cutaneous musculature

mdv - dorso-ventral musculature 


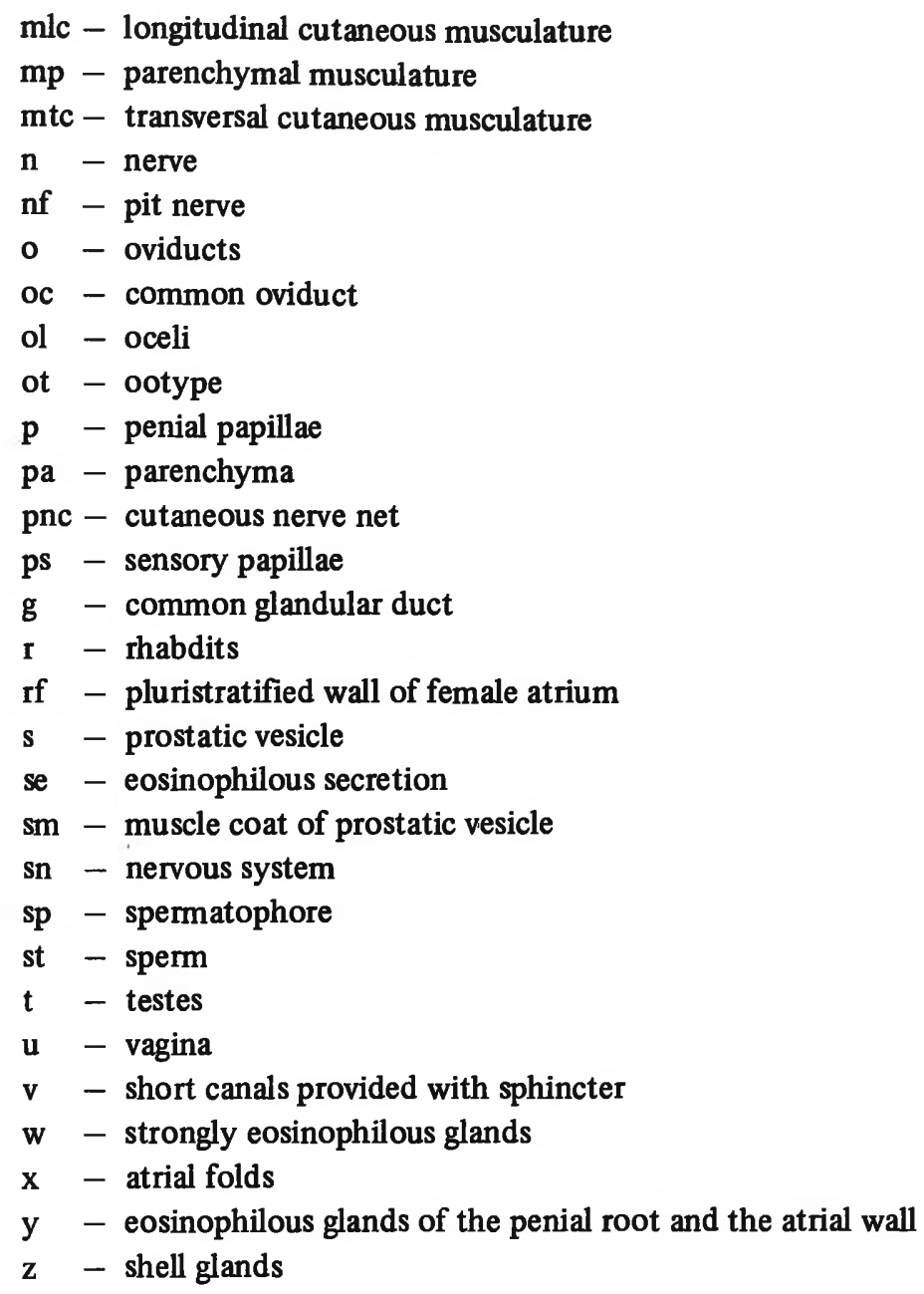


Gusana cruciata (Graff)

Figure 1 - Anterior end with the characteristic cross pattern.

Figure 2 - Ventral view of the whole worm; sensory border.

Figure 3 - Dorsal view of the whole worm; marginal eyes.

Figure 4 - Anterior end: eyes.

Figure 5 - Anterior end, ventral view: pits in the sensory border (Specimen C).

Figure 6 - Detail of sensory border transversal section, right side, showing a pit with one diverticle at each side.

Figure 7 - Right side sensory border in transverse section, showing three sensory pits:

fsr 1 , with a diverticle at the bottom, and another to the right. It is the most anterior, having begun at the same position as fsr 3 and then shifiting medially in successive transverse sections.

$\mathrm{fsr}_{2}$, with a diverticle to the left. It has, another to the right in posterior sections. It is the next to appear at the periphery.

fsr $_{3}$, beginning at the periphery. It ramifies posteriorly and medially. 


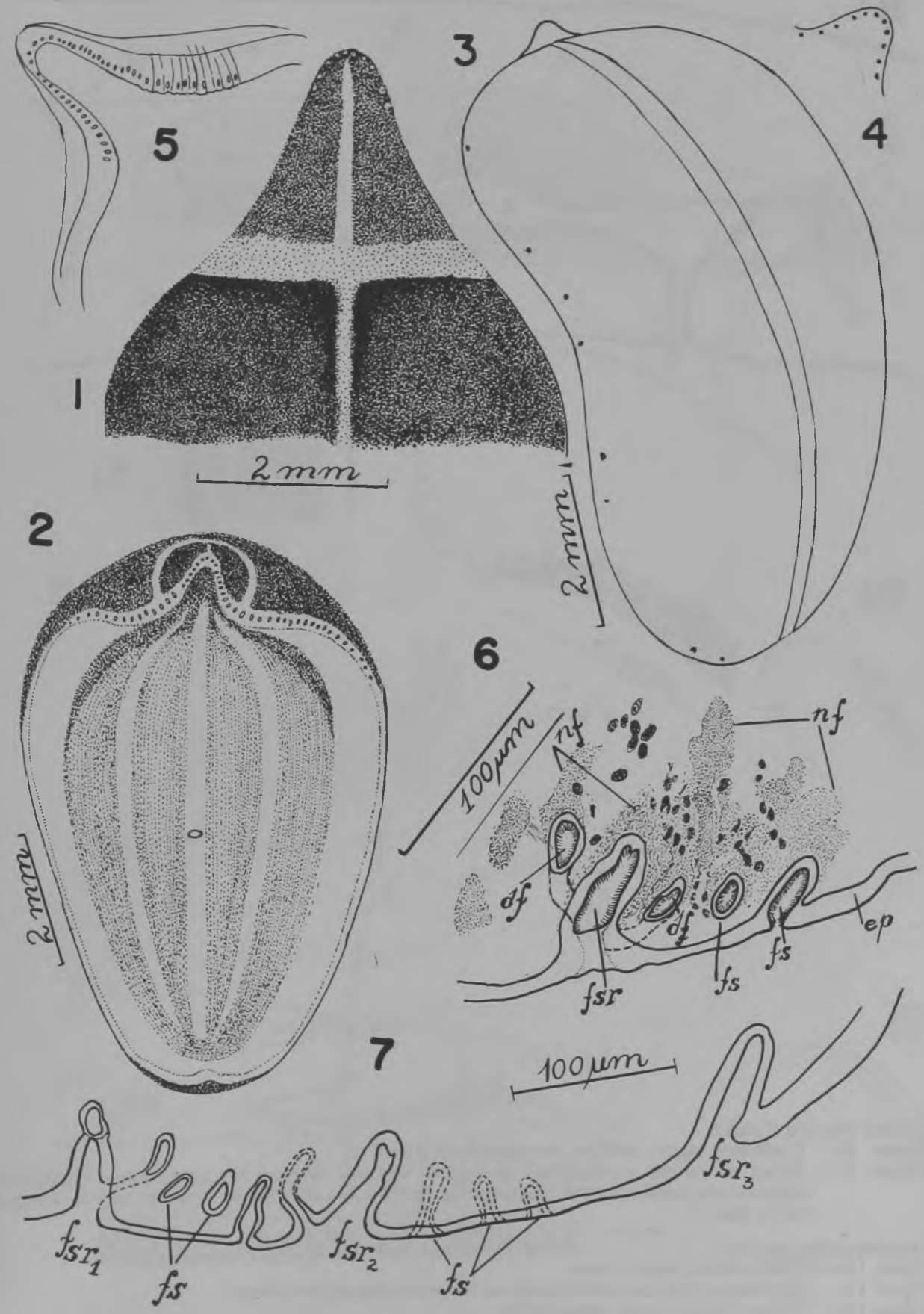


Gusana cruciata (Graff)

Figure 8 - Combined sagittal sections of copulatory complex.

Figure 9 - Detail of ventral musculature in sagittal section, showing the longitudinal cutaneous musculature sunk into the parenchyma between the cutaneous nerve net and the ventral nerve plate.

Timyma juliae, sp. nov.

Figure 10 - Whole worm, ventral view.

Figure 11 - Eyes around the anterior tip and on the left marginal dark band.

Figure 12 - Sensory border at the anterior tip.

Figure 13 - Colour pattern. 


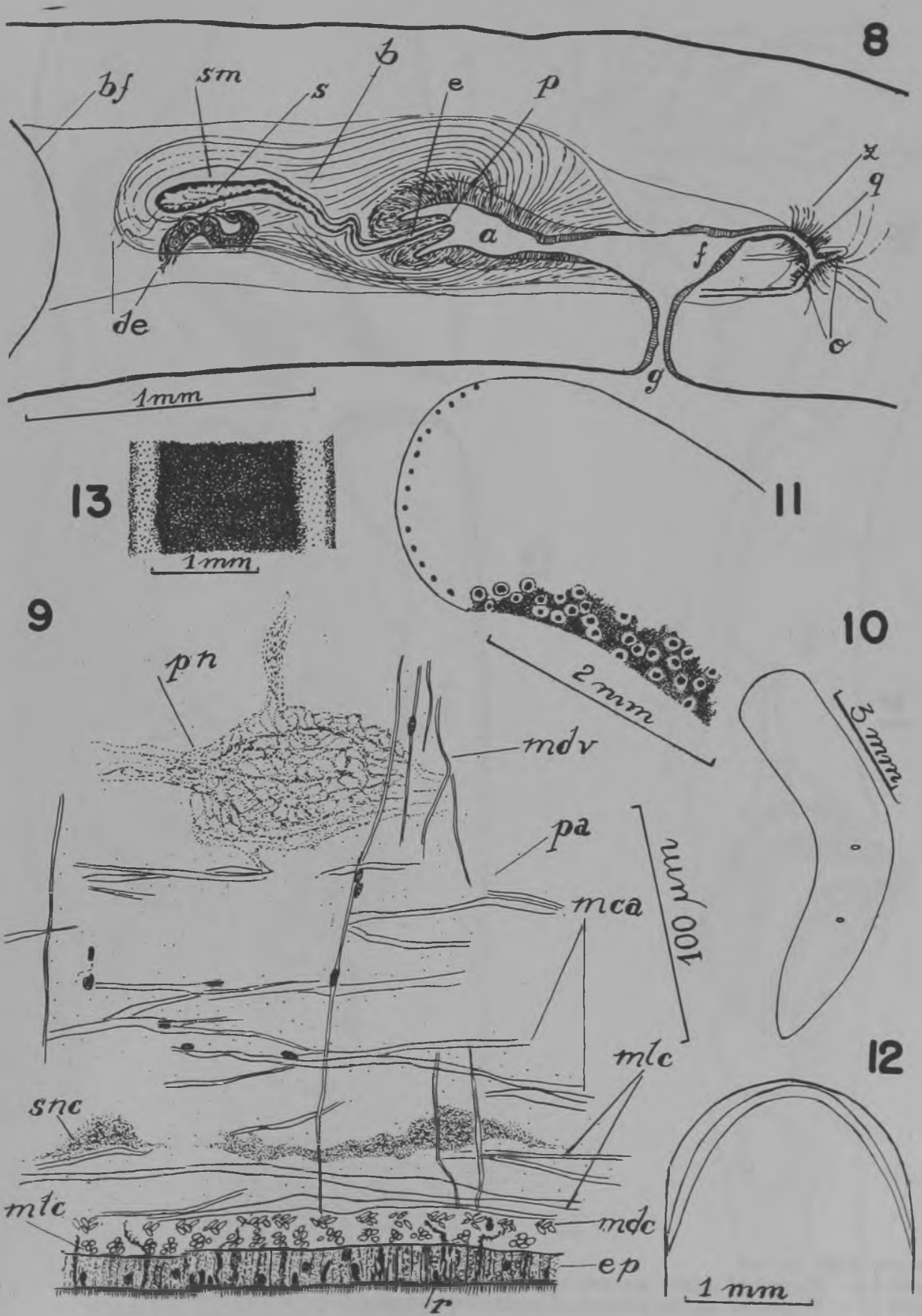


Timyma juliae, sp. nov.

Figure 14 - Combined sagittal sections of pharynx, pharyngeal pocket and testes.

Figure 15 - Combined sagittal sections of copulatory complex.

Figure 16 - Ootype, combined sagittal sections.

Figure 17 - Transverse sections posterior to copulatory complex, showing the extension of pharyngeal pocket between the two posterior intestinal arms. 


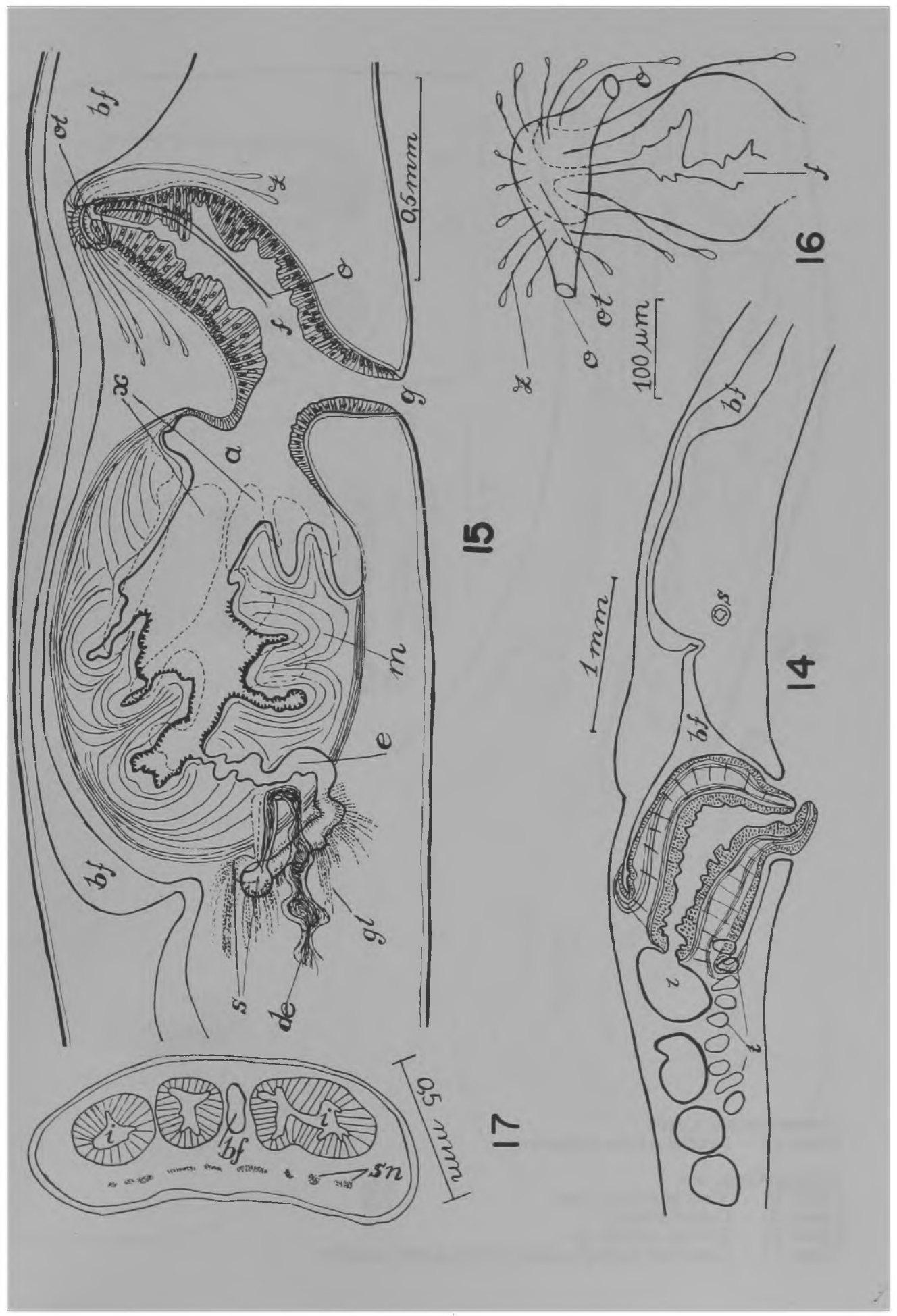


Gusana cruciata (Graff)

Figure 18 - Sagittal section of pharynx.

Liana guasa, sp. nov.

Figure 19 - View of entire worm.

Figure 20 - Colour pattern.

Figure 21 - Eyes of anterior tip.

Figure 22 - Combined sagittal sections of copulatory complex. 

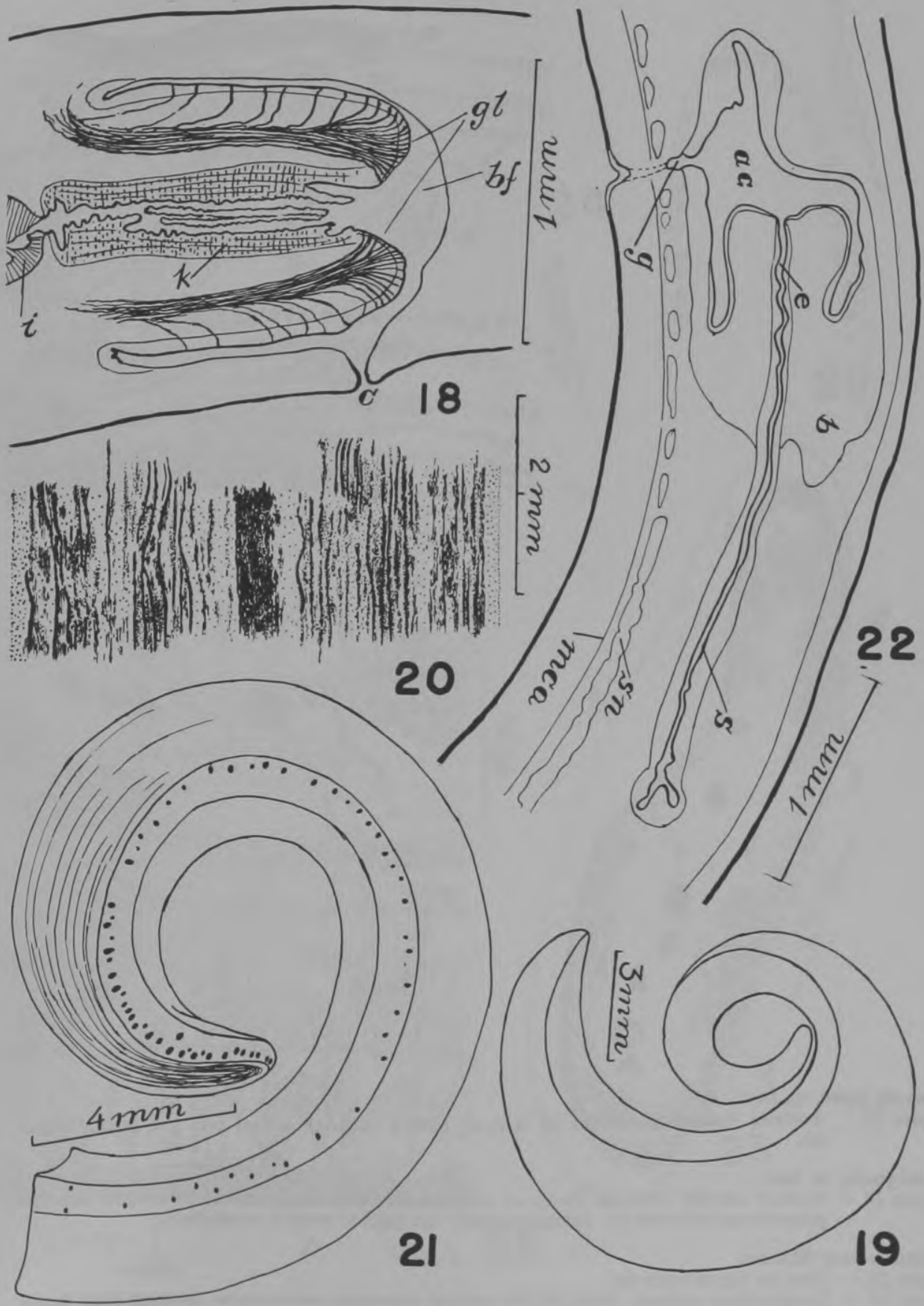
Timyma juliae, sp. nov. Figure 23 - Anterior transverse section of sensory border showing lateral pits and medial papil-
lae.

Liana guasa, sp. nov.

Figure 24 - Sagittal section showing fibres of longitudinal cutaneous musculature sunk into the parenchyma between the cutaneous nerve net and the ventral nerve plate.

Geoplana ruca (Marcus)

Figure 25 - Eyes on the anterior tip.

Figure 26 - Longitudinal section, detail of the ventral cutaneous musculature showing both layers of longitudinal fibers. 


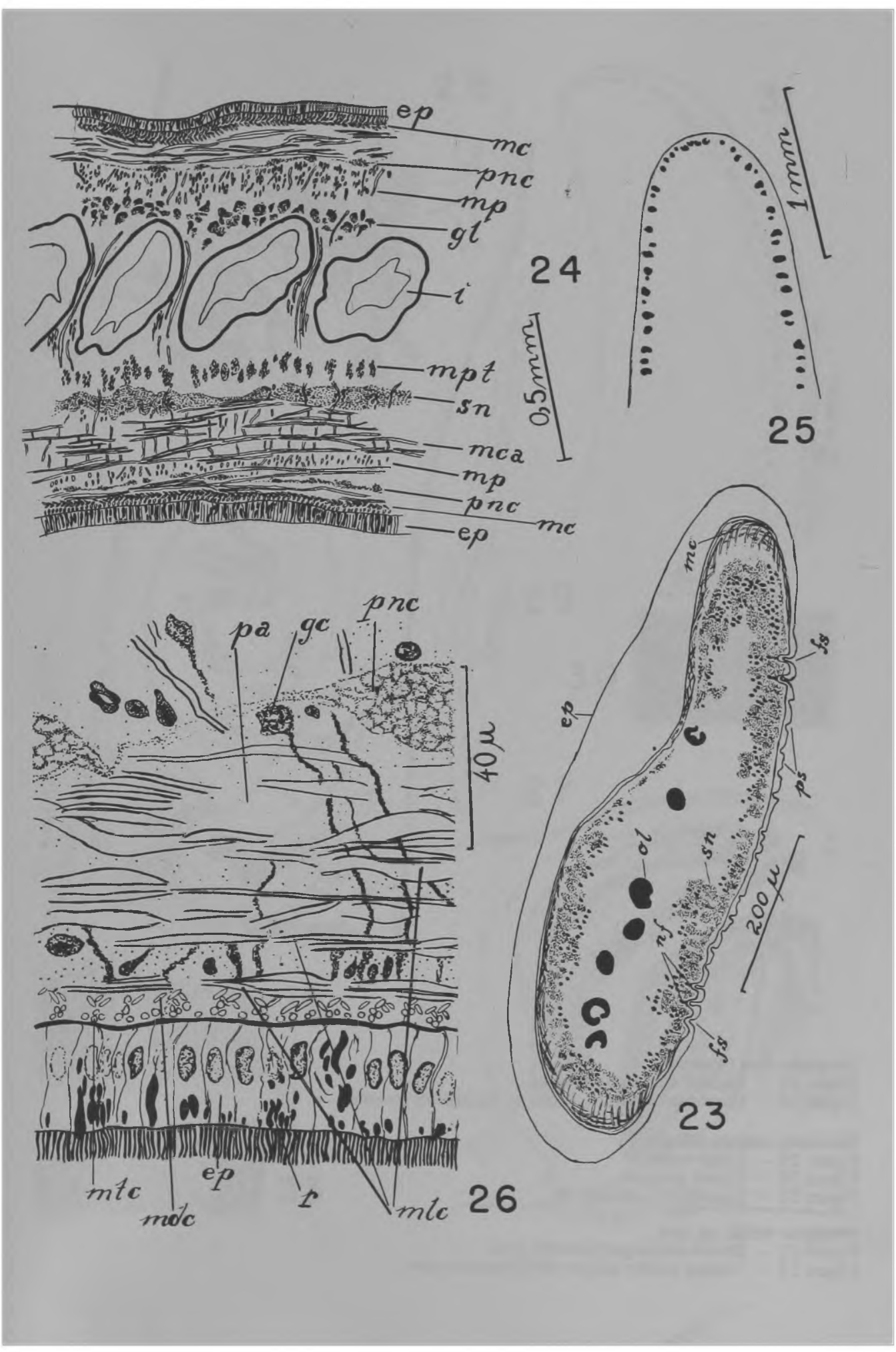


Geoplana ruca (Marcus)

Figure 27 - Sagittal section of pharynx.

Figure 28 - Combined sagittal sections of copulatory complex.

Geoplana chilensis (Graff)

Figure 29 - Entire worm.

Figure 30 - Colour pattern.

Figure 31 - Eyes on the anterior tip

Geoplana ercilla, $\mathrm{sp}_{\text {. nov. }}$

Figure 32 - Dorsal colour pattern with eyes.

Figure 33 - Ventral colour pattern with marginal eyes. 


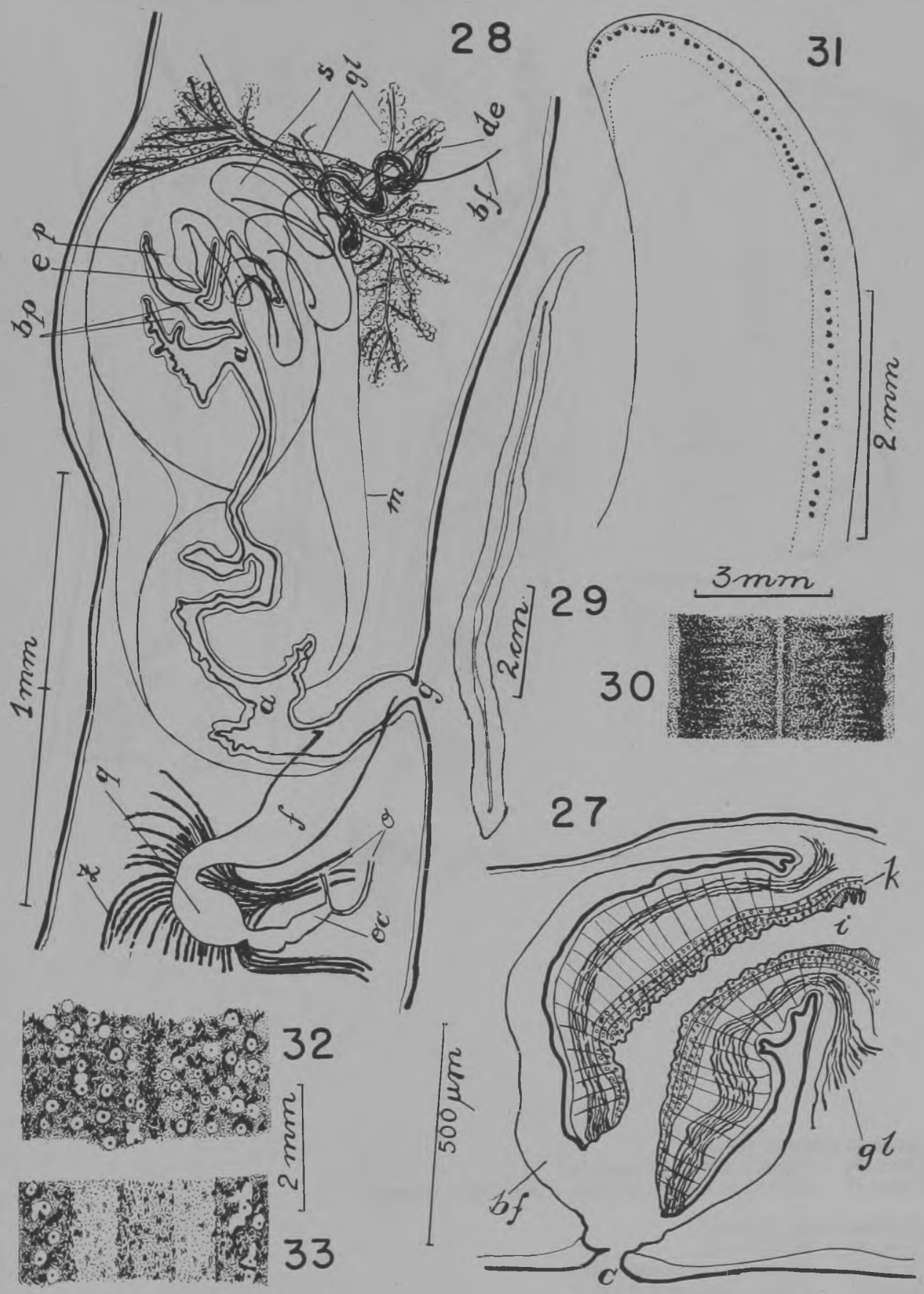


Geoplana chilensis. (Graff)

Figure 34 - Sagittal section of pharynx.

Figure 35 - Combined sagittal sections of copulatory complex

Geoplane ercilla, sp. nov.

Figure 36 - Entire worm.

Figure 37 - Shape of transversal section.

Figure 38 - Eyes on the anterior tip.

Figure 39 - View of ventral side with eyes. 


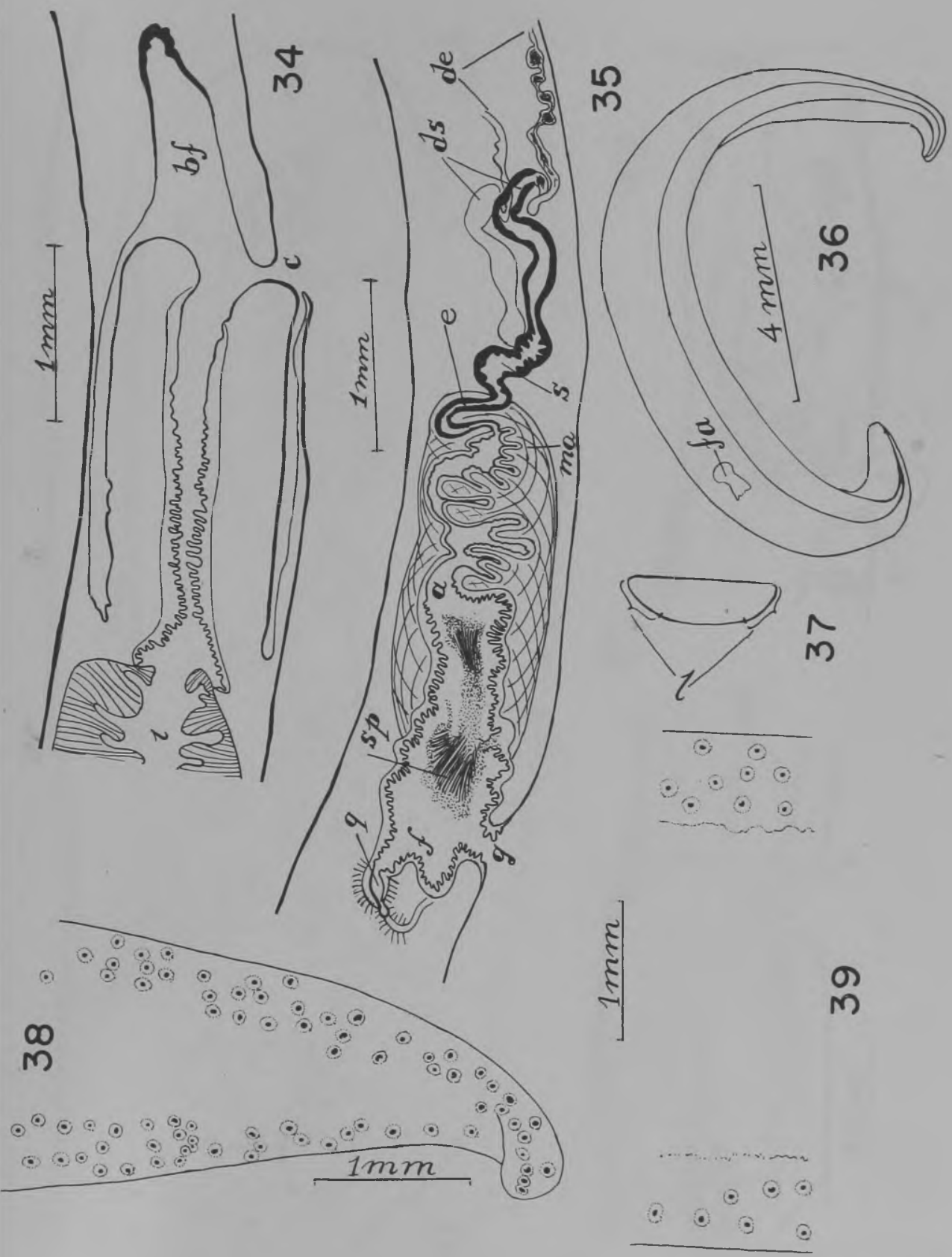


Geoplana ercilla, sp. nov.

Figure 40 - Sagittal section of pharynx.

Figure 41 - Combined sagittal sections of holotype copulatory complex.

Figure 42 - Combined sagittal sections of paratype copulatory complex. 

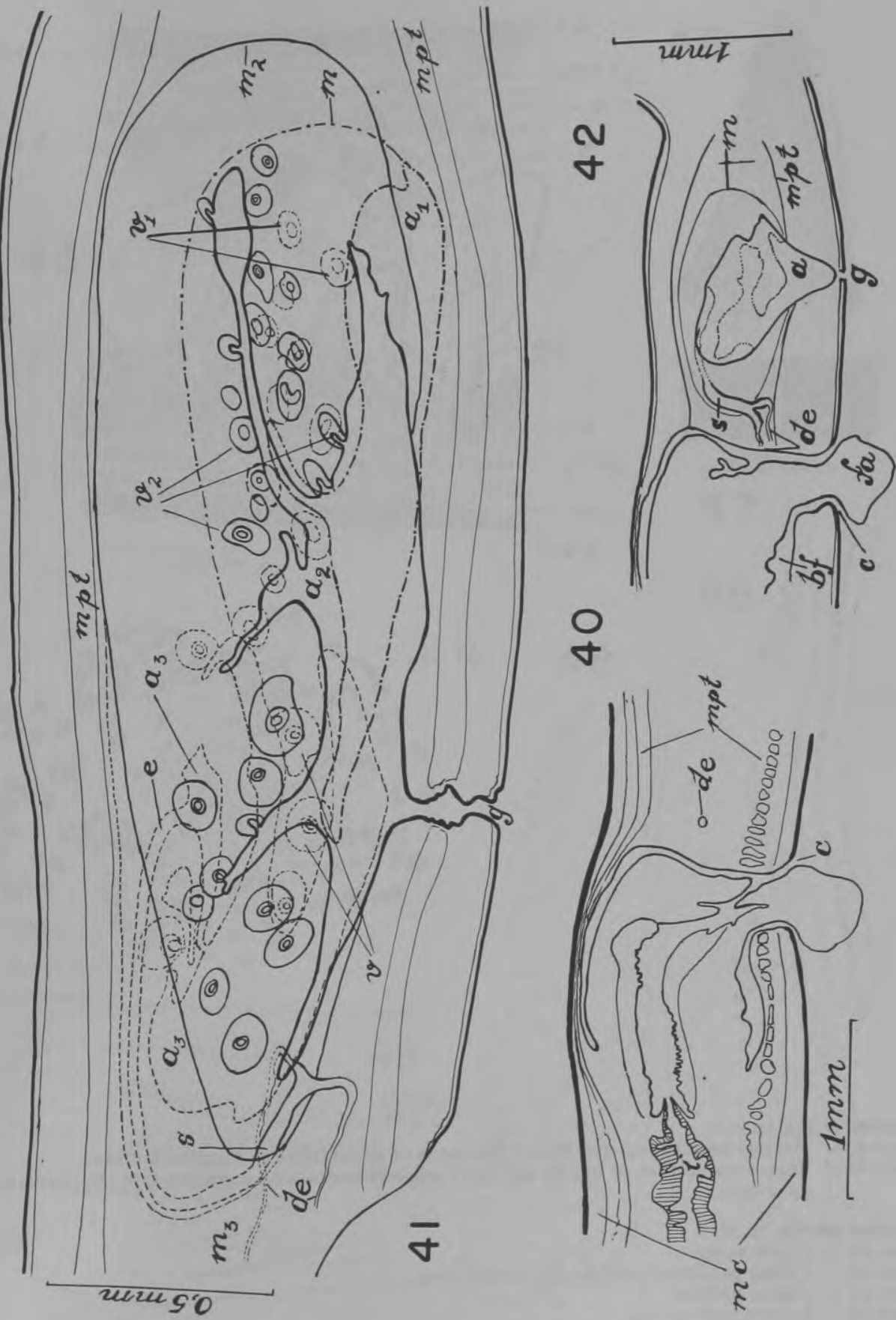
Geoplana ercilla, sp. nov.

Figure 43 - Arrangement and relative size of the layers of musculature in a sagittal section.

Figure 44 - Transverse section of one of the short canals provided with a sphincter, of the copulatory complex.

Geoplana placilla, sp. nov.

Figure 45 - Entire worm.

Figure 46 - Colour pattern of anterior tip, ventral view.

Figure 47 - Colour pattern.

Figure 48 - Eyes of anterior tip.

Figure 49 - Sagittal section of pharynx. Interrupted line reconstructed. 


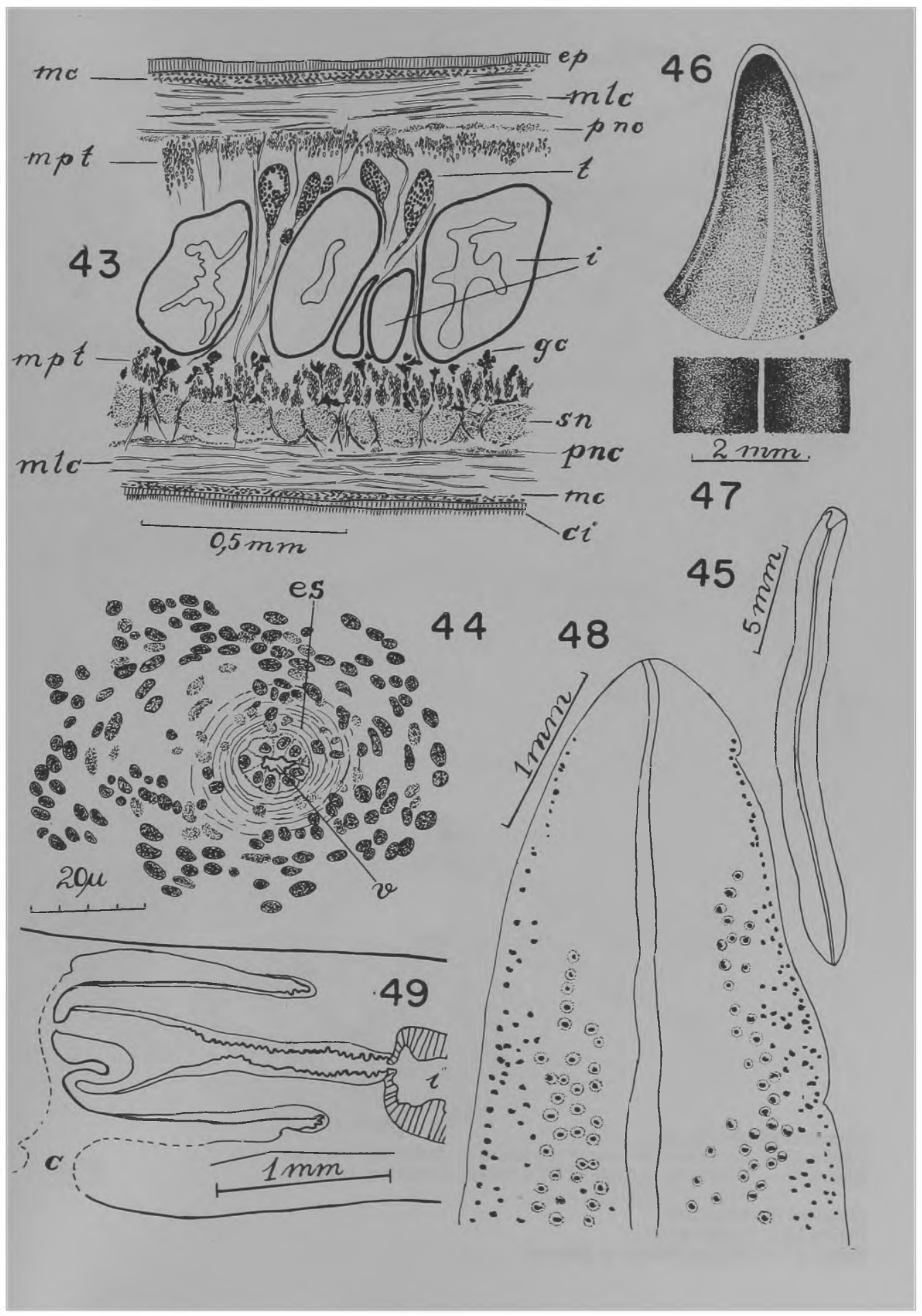


Geoplane placilla, sp. nov.

Figure 50 - Combined sections of the holotype copulatory complex.

Figure 51 - Combined sections of the paratype copulatory complex.

Geoplana chanca, sp. nov.

Figure 52 - Entire worm.

Figure 53 - Sagittal section of pharynx. 


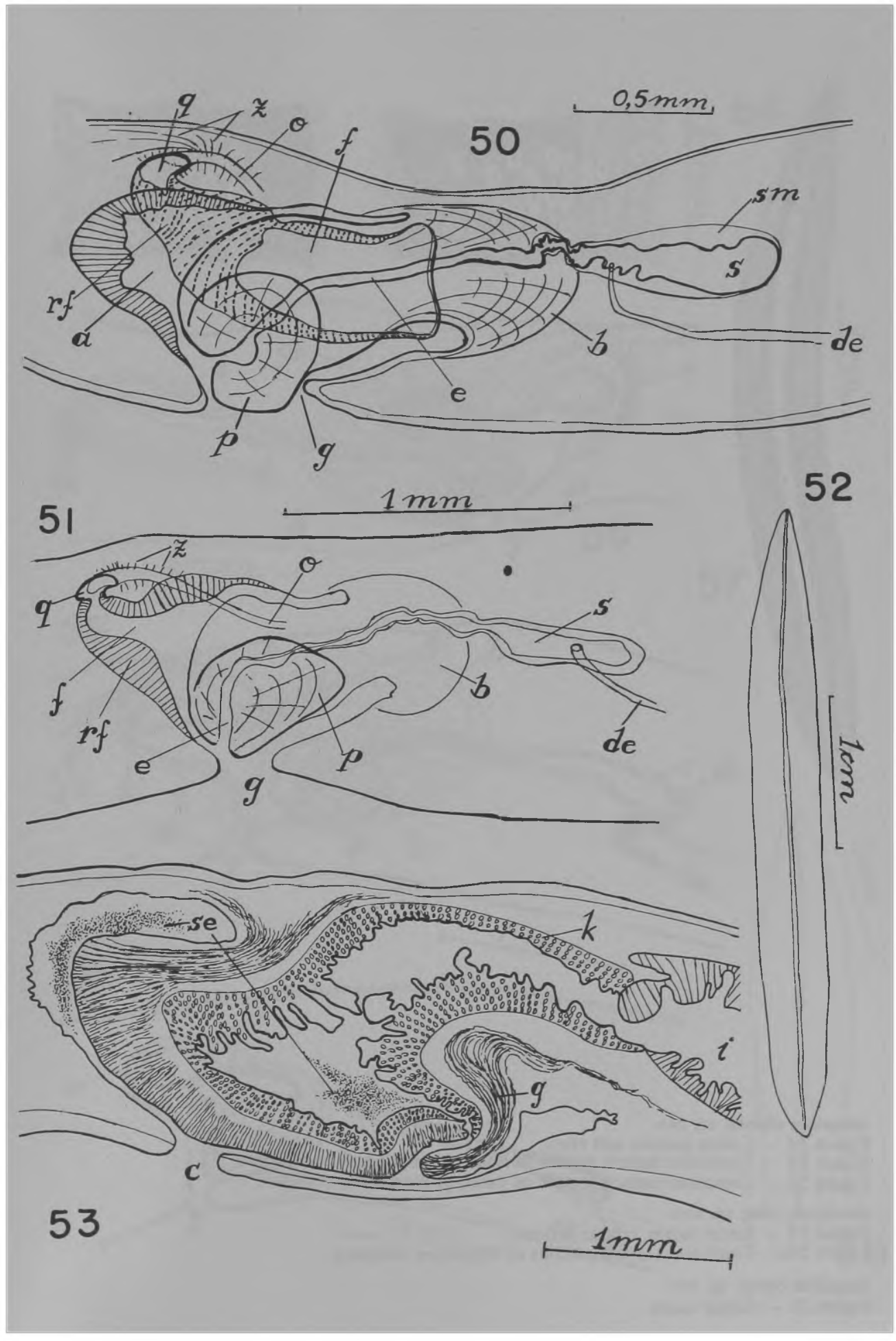


Geoplana chanca, sp. nov.

Figure 54 - Colour pattern and eyes.

Figure 55 - Combined sagittal section of holotype copulatory complex.

Figure 56 - Combined sagittal section of paratype copulatory complex.

Geoplana tirua, sp. nov.

Figure 57 - Entire worm, colour pattern.

Figure 58 - Combined sagittal sections of copulatory complex.

Geoplana caleta, sp. nov

Figure 59 - Entire worm. 

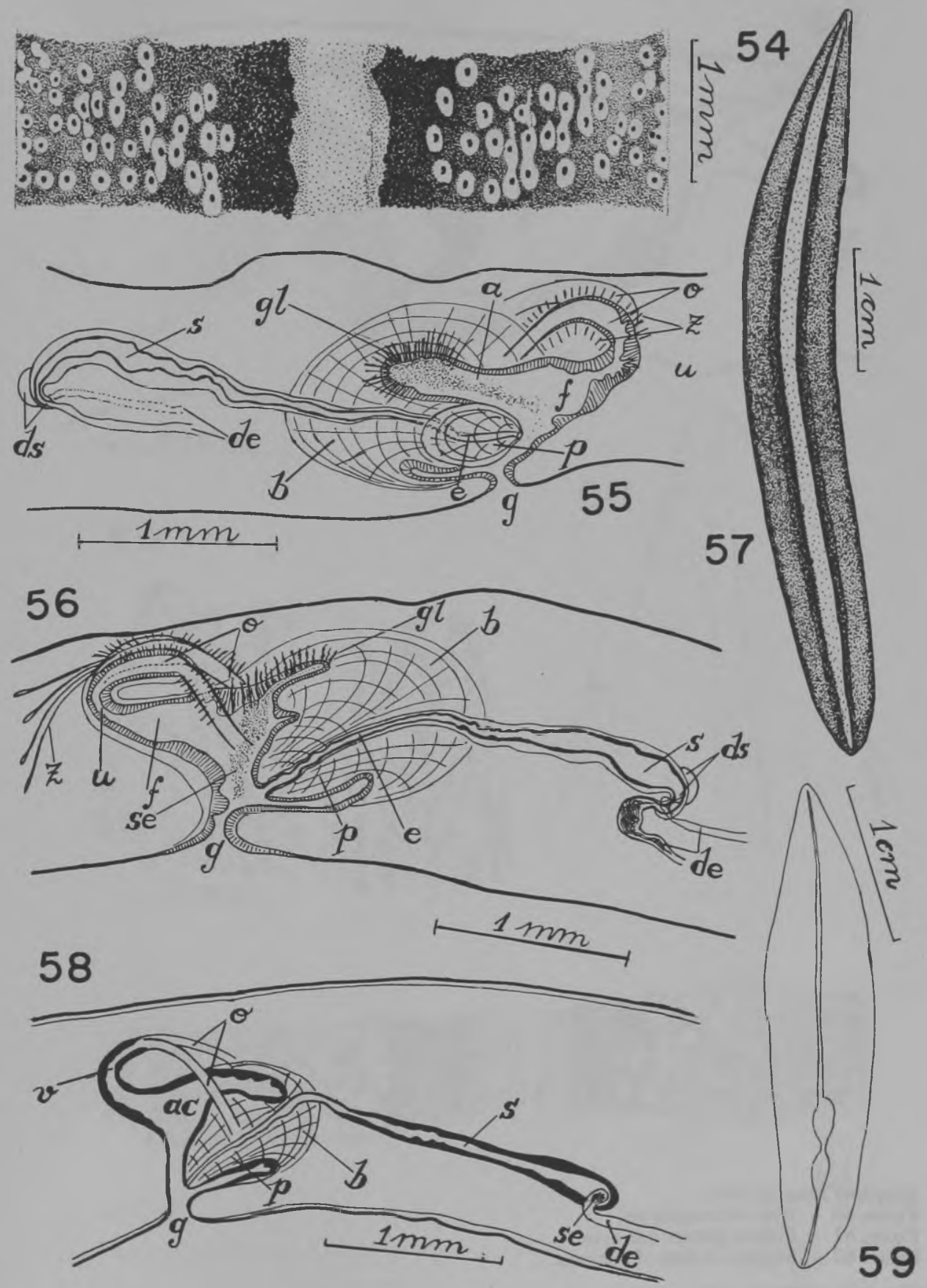
Geoplana tirua, sp. nov.

Figure 60 - Eyes of anterior tip.

Figure 61 - Colour pattern and eyes.

Figure 62 - Sagittal section of pharynx.

Geoplana caleta, sp. nov.

Figure 63 - Colour pattern. 

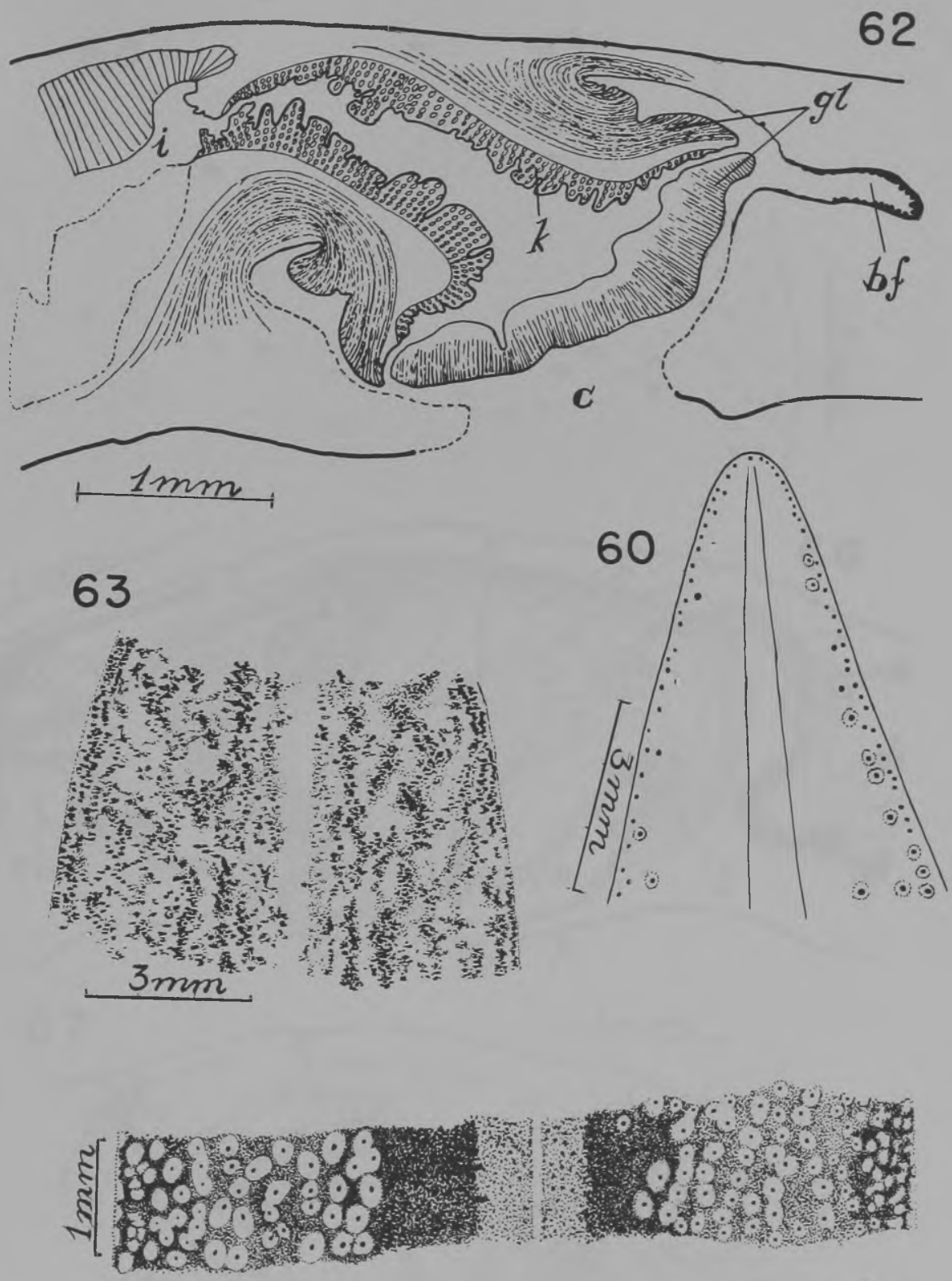
Geoplana caleta, sp. nov.

Figure 64 - Eyes, on the right side, $5 \mathrm{~mm}$ from the anterior tip. The whole width of the worm

Figure 65 - Three lobed eyes on the right side, 7,5 $\mathrm{mm}$ from the anterior tip. The whole width of the worm at this level is $7,3 \mathrm{~mm}$.

Figure 66 - Combined sagittal section of holotype copulatory complex.

Figure 67 - Combined sagittal section of paratype copulatory complex. 


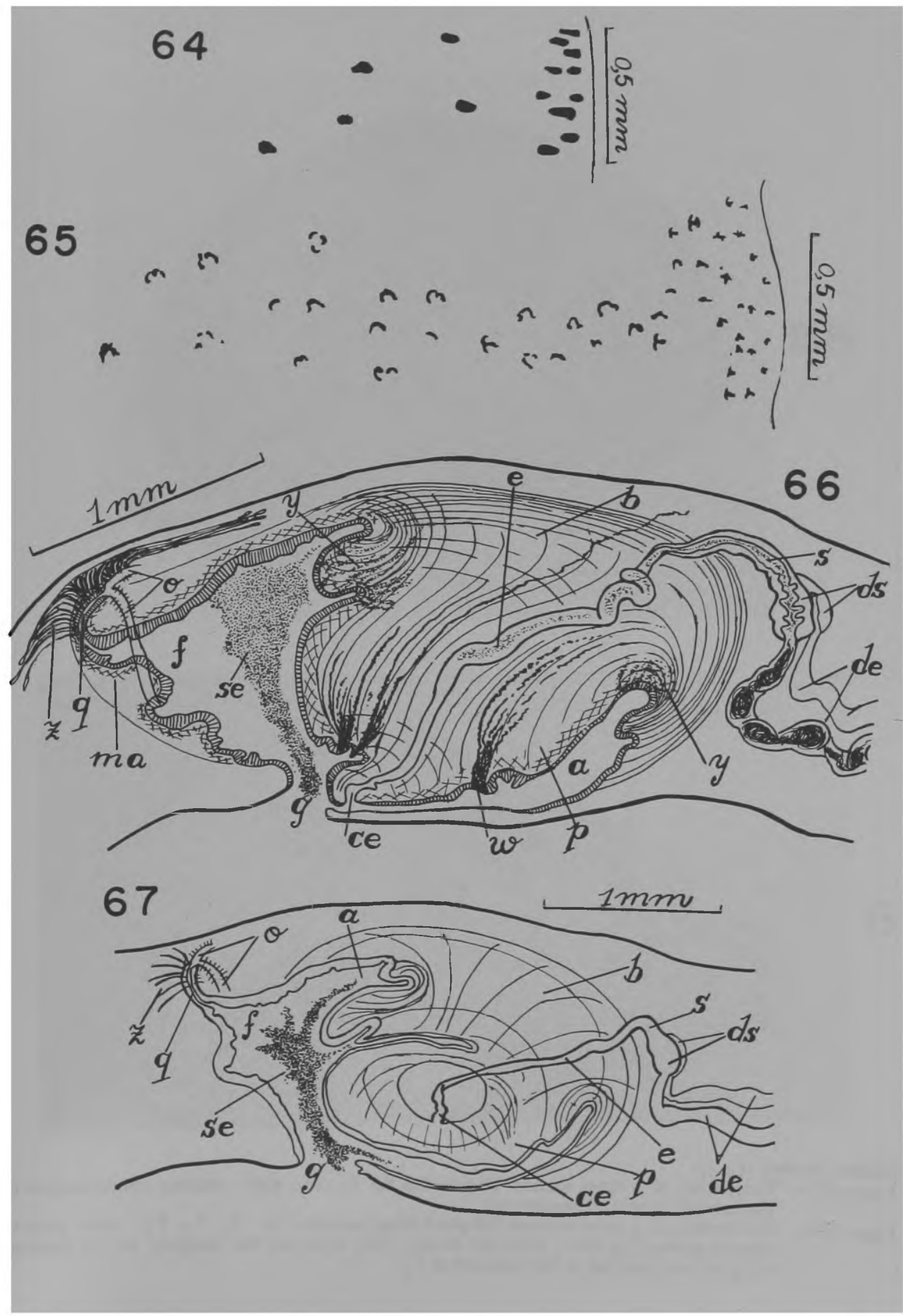


Gusana cruciata (Graff)

Figure 68 - Photomicr. of a cross section $78 \mu \mathrm{m}$ the tip. E: eye; ANC: anterior concentration of the nervous system; P: sensory pit.

Figure 69 - Photomicr. of a cross section $708 \mu \mathrm{m}$ behind anterior tip. $\mathbf{P}_{1}, \mathrm{P}_{2}, \mathrm{P}_{3}$ : three pairs of sensory grooves in three different levels. They begin on the margins, on the position of $P_{3}$ and end mediad in the position of $P_{1}$. 

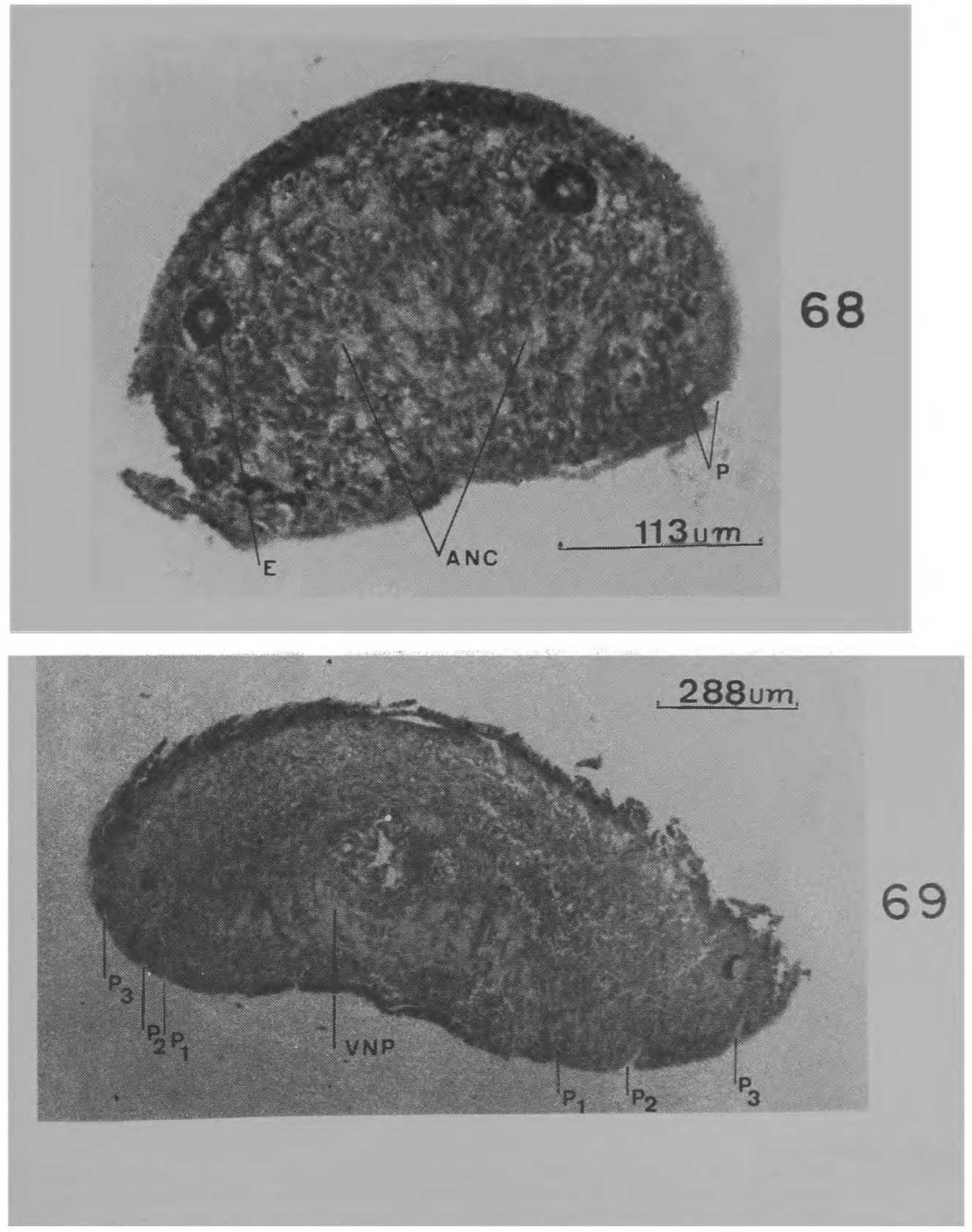


\section{Gusana cruciata (Graff)}

Figure 70 - Photomicr. of a detail of sensory border on the right side of across section $774 \mu \mathrm{m}$ behind the anterior tip. $\mathrm{BP}$ : branched sensory pit; $\mathbf{P}_{1}$ : sensory groove beginning margi-
nally; $\mathrm{P}_{2}$ : sensory groove ending mediad.

Figure 71 - Photomicr. of a detail of sensory border on the right of a cross section $798 \mu \mathrm{m}$ behind the anterior tip. $P_{1}-P_{9}$ : sensory pits; $P_{2}$ and $P_{3}$, respectively, dorsal and right diverticles of $P_{1}$. 

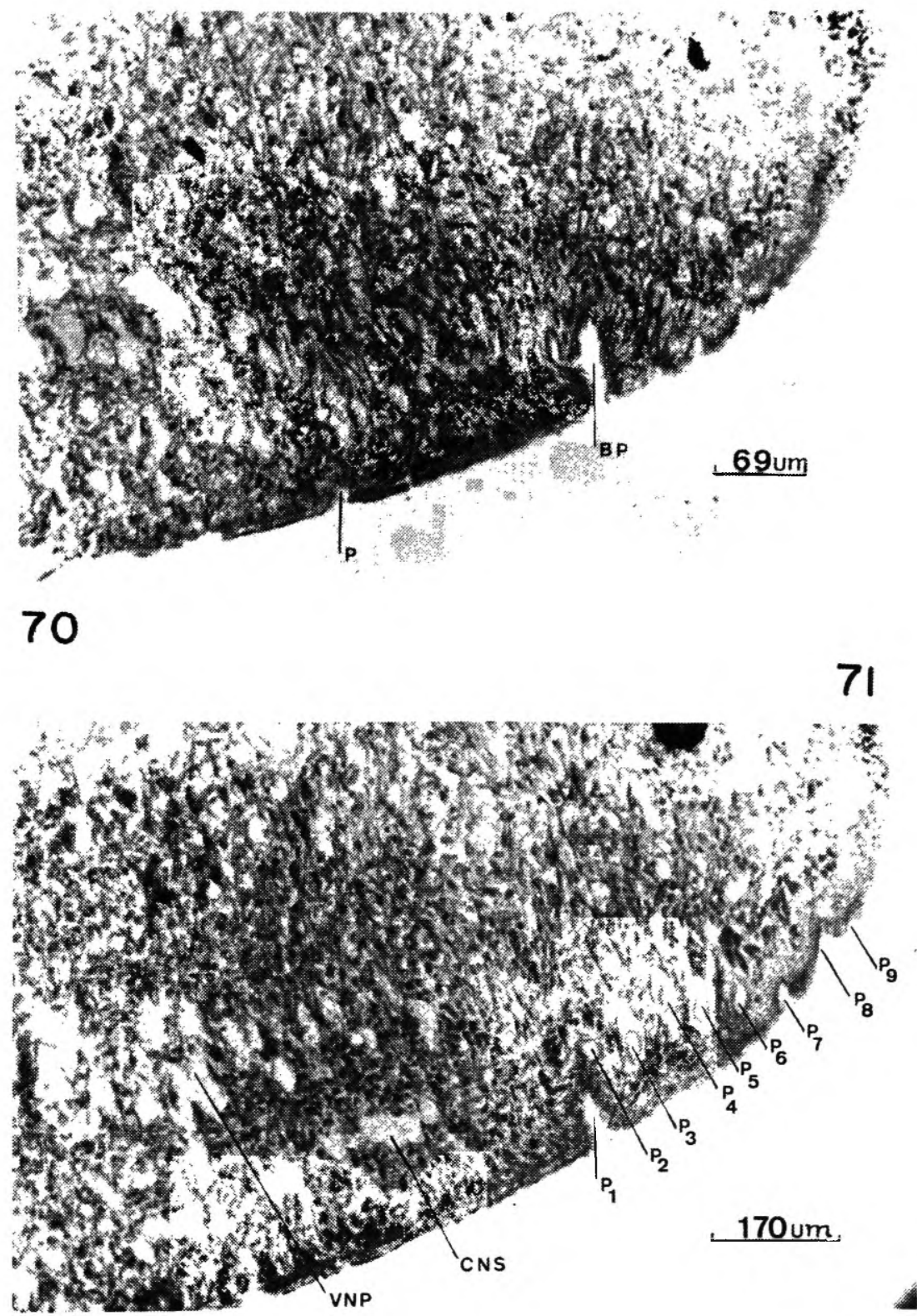
Timyma juliae, sp. n.

Figure 72 - Photomicr. of a cross section $30 \mu \mathrm{m}$ behind anterior tip showing sensory border with four pairs of sensory pits marginally and furrows and papillae medially.

$\mathrm{E}$ : eyes bordering anterior tip; P: sensory pits; SBF : internal furrows of sensory border; SBP: sensory papillae.

Figure 73 - Photomicr. of a cross.section $54 \mu \mathrm{m}$ behind anterior tip; detail of sensory border of the left side.

P: sensory pits; SBP: papillae of sensory border. 

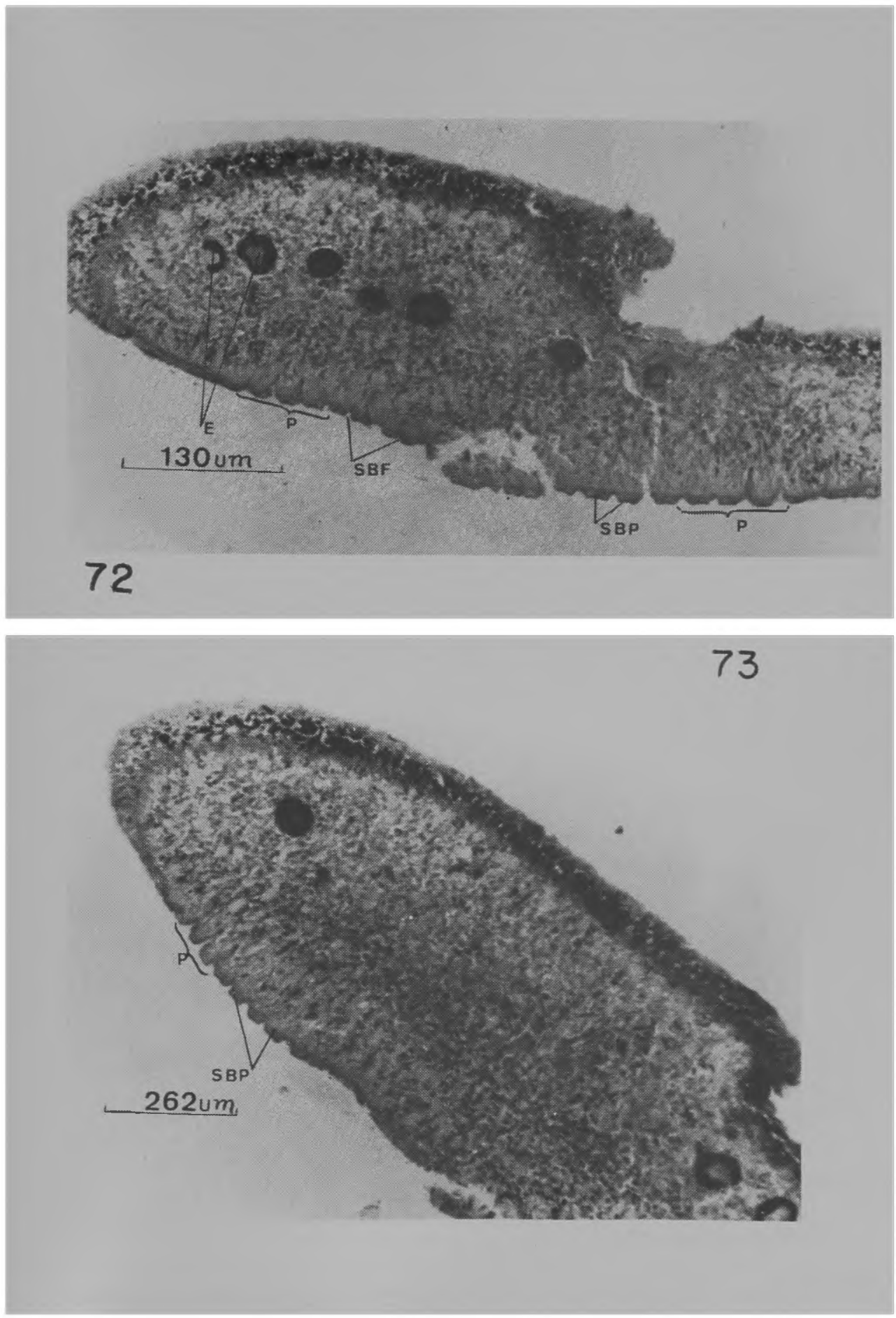
Timyma juliae, sp. n.

Figure 74 - Photomicr. of a cross section $198 \mu \mathrm{m}$ behind the tip; detail of sensory border of right side, SB: sensory border; R: band rhabdites bordering internally the sensory border; VNP: ventral nerve plate.

Liana guasa, sp. n.

Figure 75 -- Photomicr. of a sagittal section. CNS: cutaneous nerve net; MLC: longitudinäl cutaneous musculature; MLP: longitudinal parenchymal musculature; VNP: ventral nerve plate. 


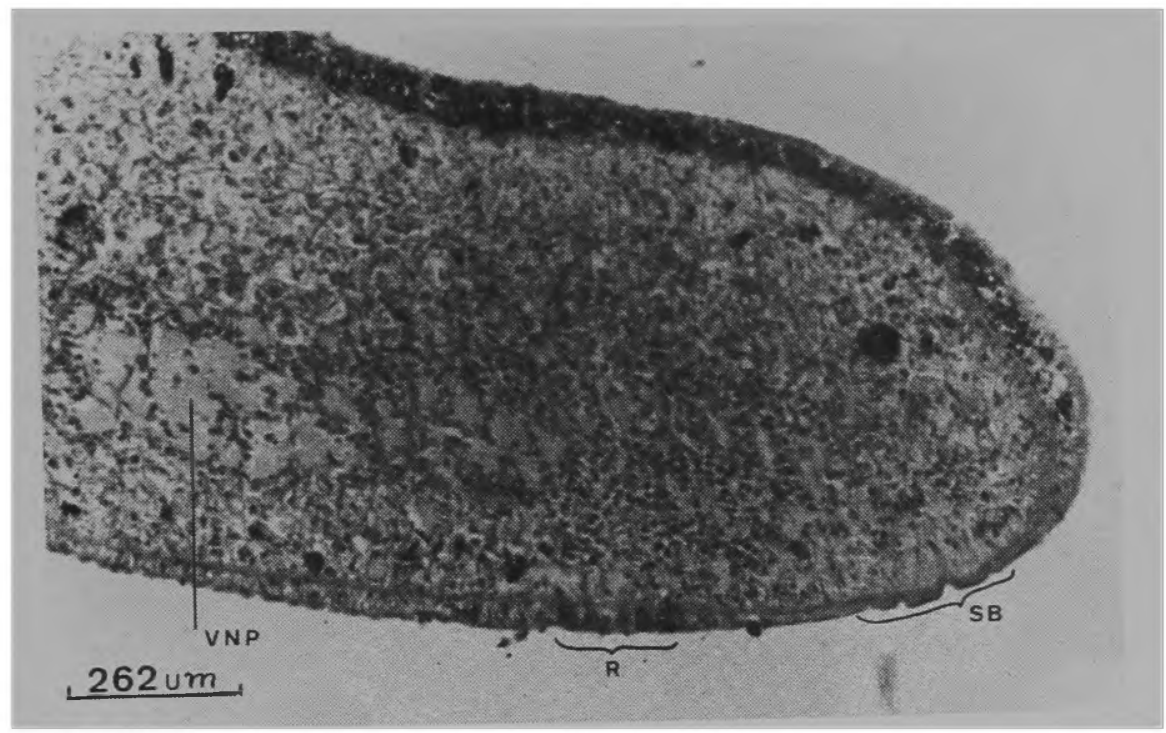

74

75

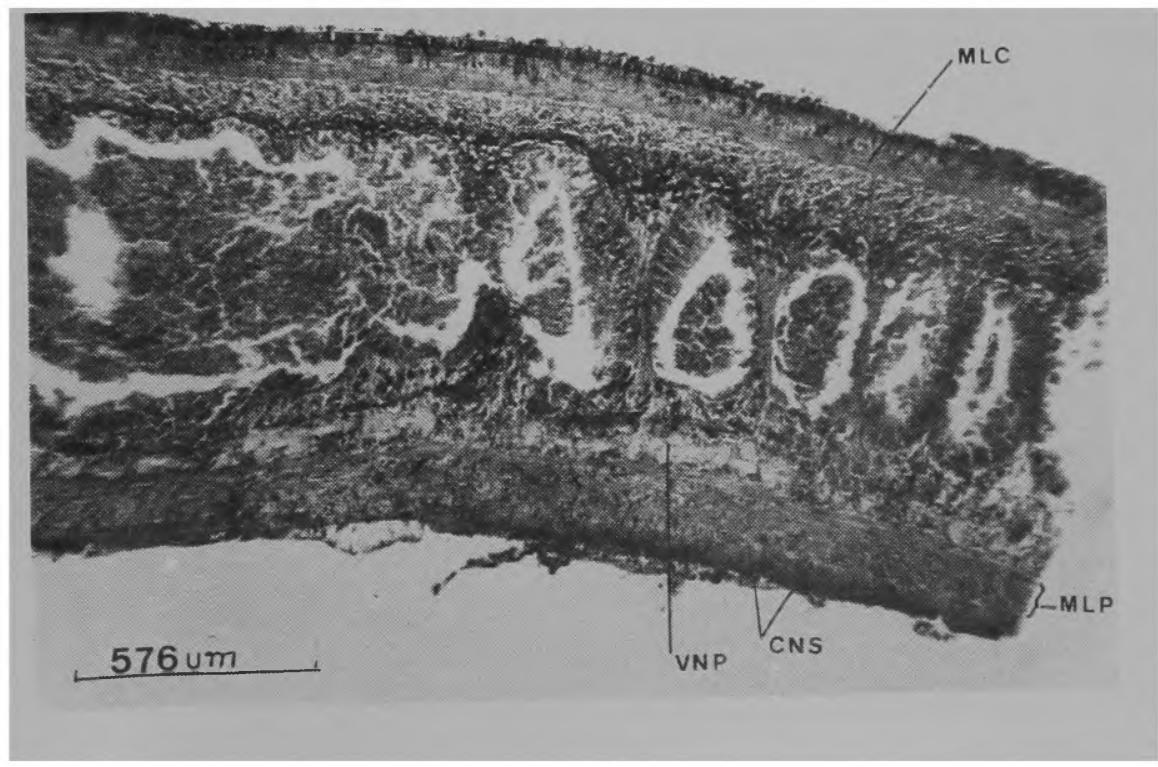


Liana guasa, sp. n.

Figure 76 - Photomicr. of a sagittal section; detail of ventral side.

BM: basement membrane; CNS: cutaneous nerve net; MLC: longitudinal cutaneous musculature; MLP: longitudinal parenchymal musculature; VNP: ventral nerve plate; $\mathrm{X}$ : longitudinal muscles bundles entering parenchym from cutaneous layer.

Geoplana ruca (Marcus)

Figure 77 - Photomicr. of sagittal section; detail of the ventral side.

C: cilia; BM: basement membrane; CNS: cutaneous nerve net; MLC: first layer of longitudinal cutaneous musculature; $\mathrm{MLC}_{2}$ : second layer of longitudinal cutaneous musculature. 


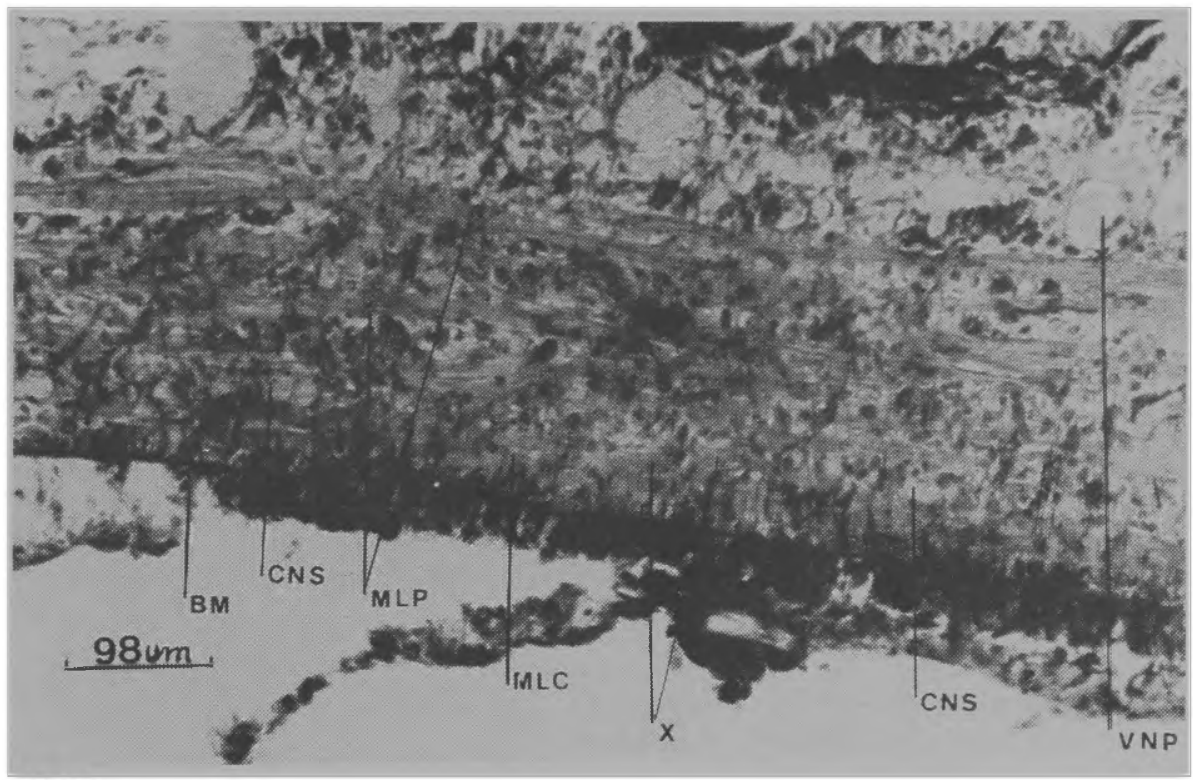

76

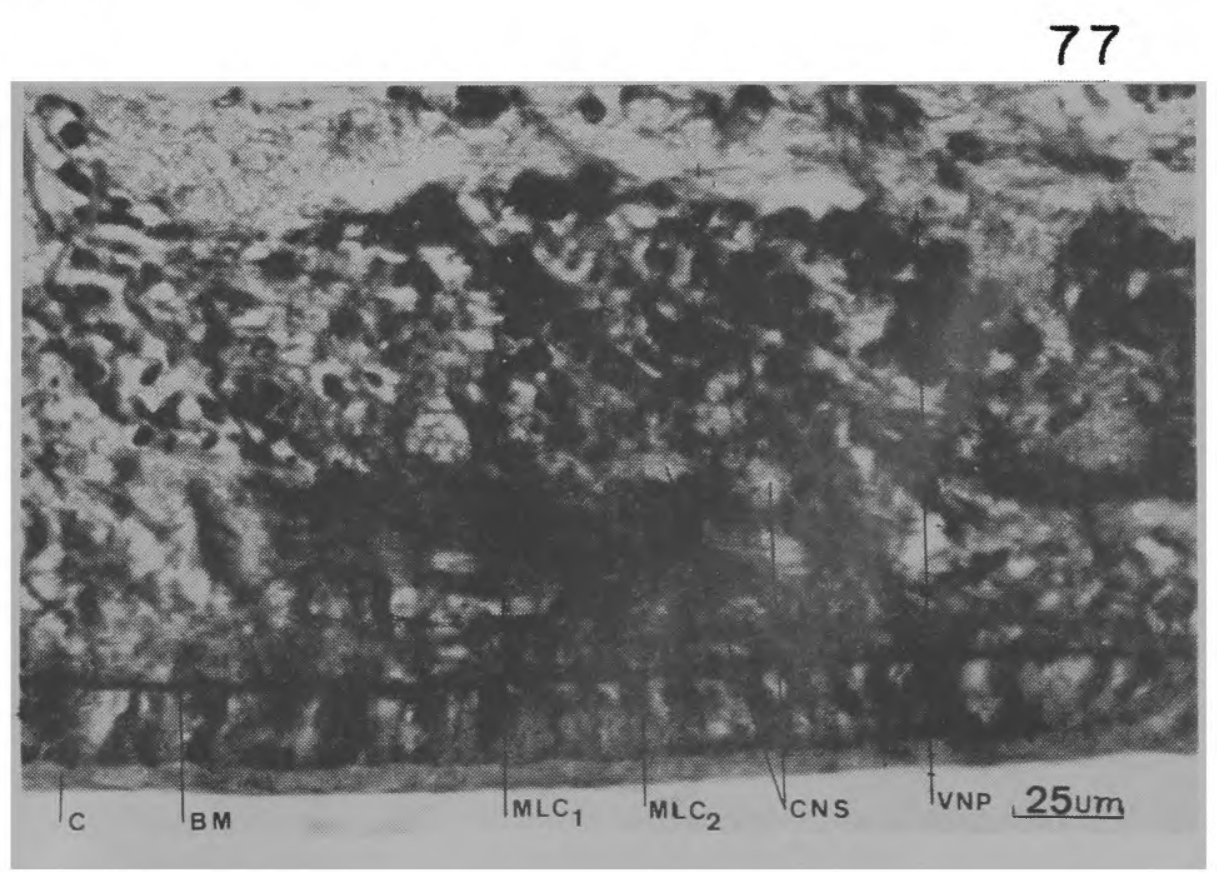


